\title{
An updated probabilistic seismic hazard assessment for Romania and comparison with the approach and outcomes of the SHARE project
}

\author{
Florin Pavel ${ }^{1}$, Radu Vacareanu ${ }^{1}$, John Douglas ${ }^{2}$, Mircea Radulian ${ }^{3,4}$, Carmen Cioflan ${ }^{3}$, Alex Barbat ${ }^{5}$ \\ ${ }^{1}$ Seismic Risk Assessment Research Centre, Technical University of Civil Engineering Bucharest, Bd. \\ Lacul Tei no. 122-124, Sector 2, Bucharest, 020396, Romania \\ ${ }^{2}$ Department of Civil and Environmental Engineering, University of Strathclyde, James Weir Building, 75 \\ Montrose Street, Glasgow, G1 1XJ, United Kingdom \\ ${ }^{3}$ National Institute of Earth Physics (NIEP), P.O. Box MG-2, RO-077125 Bucharest-Măgurele, Romania \\ ${ }^{4}$ Academy of Romanian Scientists, 54 Splaiul Independentei, RO-050094 Bucharest, Romania ${ }^{5}$ Technical \\ University of Catalonia UPC, Module C1, Campus Norte UPC Jordi Girona 1-3, Barcelona, 08034, Spain
}

Corresponding author e-mail: florin.pavel@utcb.ro

\begin{abstract}
The probabilistic seismic hazard analysis for Romania is revisited within the framework of the BIGSEES national research project (http://infp.infp.ro/bigsees/default.htm) financed by the Romanian Ministry of Education and Scientific Research in the period 2012-2016. The scope of this project is to provide a refined description of the seismic actions for Romanian sites according to the requirements of Eurocode 8 . To this aim, the seismicity of all the sources influencing the Romanian territory is updated based on new data acquired in recent years. The ground-motion models used in the analysis, as well as their corresponding weights, are selected based on the results from several recent papers also published within the framework of the BIGSEES project. The seismic hazard analysis for Romania used in this study are based on the traditional Cornell-McGuire approach. Finally, the results are discussed and compared with the values obtained in the recently-completed SHARE research project. The BIGSEES and SHARE results are not directly comparable since the considered soil conditions are different - actual soil classes for BIGSEES and rock for SHARE. Nevertheless, the analyses of the seismic hazard results for 200 sites in Romania reveal considerable differences between the seismic hazard levels obtained in the present study and the SHARE results and point out the need for further analyses and thorough discussions related to the two seismic hazard models, especially in the light of a possible future harmonized hazard map for Europe.
\end{abstract}

Keywords Seismic source, ground motion model, acceleration response spectra, soil class, exceedance probability, uncertainty, SHARE project.

\section{Introduction}

Seismic hazard analysis can be approached in a deterministic or a probabilistic manner, the latter being fully described in many references (e.g. Cornell, 1968; Reiter, 1990; Kramer, 1996; McGuire, 2004). Probabilistic seismic hazard analysis (PSHA) is performed for a site by considering all the ground motions occurring from earthquakes having a magnitude ranging from a lower to an upper bound and source-to-site distances within active seismic source(s), along with considering their associated variabilities and uncertainties.

PSHA has the advantage of fully integrating all the aleatory variabilities arising from seismicity and ground-motion levels expected from a future earthquake at a particular site. Epistemic uncertainties can be included through the use of a logic tree approach (e.g. Kulkarni et al. 1984; Coppersmith and Youngs 1986; Bommer et al. 2005; Bommer and Scherbaum, 2008)..

Several deterministic and probabilistic seismic hazard assessments for Romania in terms of horizontal peak ground acceleration and/or macro-seismic intensities have been published since 1999 (e.g. Lungu et 
al. 2006; Musson 2000; Mäntyniemi et al. 2003; Sokolov et al. 2009; Vacareanu et al. 2014). A more complete list of these studies, over 15 at this time, can be found in Vacareanu et al. (2014).

The focus of the present study is to provide an updated seismic hazard model for Romania based on the traditional Cornell-McGuire approach and explore some of its most significant results. The model was developed within the framework of the BIGSEES national research project in which the National Institute of Earth Physics and the Technical University of Civil Engineering Bucharest are the main contributors. The updated seismic hazard model (with respect to previous studies performed for Romania) includes a refined analysis of the seismicity of Romania and uses ground-motion models selected based on groundmotion recordings collected during both intermediate-depth Vrancea earthquakes, as well as during shallow crustal seismic events.

This study comprises two parts. In the first part, an updated seismic hazard analysis for Romania is performed by using the information gathered within the BIGSEES national research project (http://infp.infp.ro/bigsees/default.htm). One of the most important objectives of the BIGSEES Project is to provide a refined and updated seismic hazard map altogether with the parameters that define the design response spectra necessary for a further revision of the seismic design code in Romania (code P1001/2013 enforced since January 2014). In the second part of the article, the seismic hazard results for Romania are assessed and compared with some of the results obtained in the pan-European SHARE project (Woessner et al. 2015; Weatherhill and Danciu 2014; Silva et al. 2014). The results computed using the two seismic hazard models (BIGSEES and SHARE) point to the need for further analyses, discussions and clarifications, especially in the light of a possible future pan-European seismic hazard map based on SHARE results.

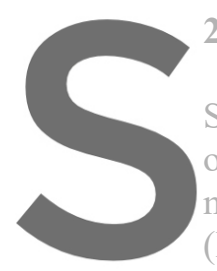

2. Seismic sources and

Seismic sources are the

of a seismic source depenc

mantle and which show

(Basili et al. 2009): (1)
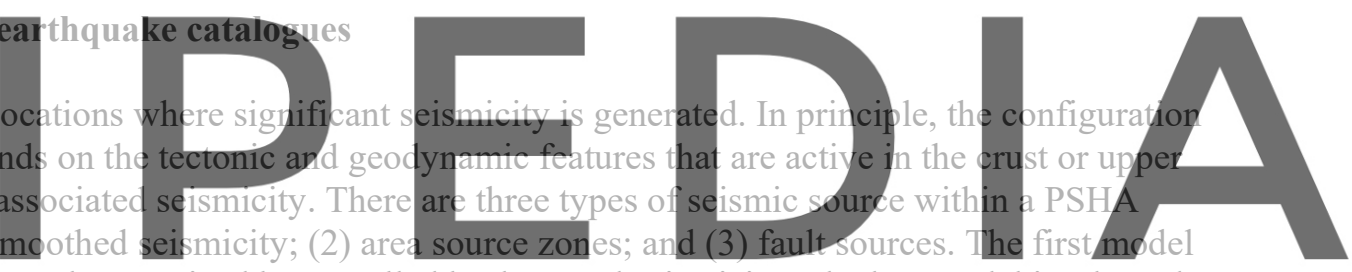

is commonly used for areas characterized by so-called background seismicity. The last model is adopted

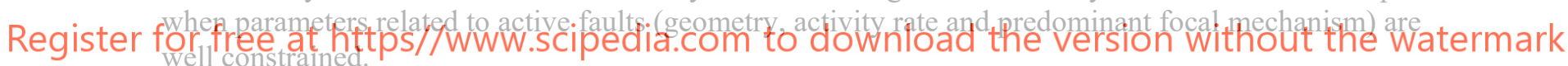

Since for Romania many of the active faults are buried and covered by sedimentary layers and the seismic activity is usualiy spread out over multiple-branched fault systems, we adopt the approach of source zones. Source zones represent areas of homogeneous seismicity in terms of activity rates and frequencymagnitude distributions. Outside the considered area sources, a background seismicity model which covers the remaining territory of Romania is applied. The background seismicity model is based on the recorded instrumental seismicity in each region of Romania.

A zoneless model based on the density distribution of the recent earthquakes was considered at some point but since there are large uncertainties in the position of the epicentres for the historical earthquakes and, in addition, the recent seismicity lacks medium and large magnitude crustal earthquakes, we decided to disregard this approach and instead focus on a more traditional areal sources approach.

The seismic sources contributing to the earthquake hazard of Romania are defined in Figure 1: 13 sources of crustal depths and one of intermediate-depth seismicity in the Vrancea region. In Figure 1 are also shown the 20 cities in Romania with more than 100000 inhabitants. Largely, the sources are the same as defined by Radulian et al. (2000), keeping the same stress field characteristics. Their geometries have been slightly refined, however, to take into account the distribution of recent seismicity and the revision of historical earthquakes, recently carried out within the SHARE project (Stucchi et al. 2013).

The stress regime (Radulian et al. 2000) is mainly of extensional type for most of the seismic sources in Romania and Bulgaria, with the exception of the Banat, Crisana-Maramures and Vrancea seismic sources (both crustal and intermediate-depth). Some more details of the stress patterns in Romania can be found in Radulian et al. (2000). 
Geodynamic models for Romania first refer to the active tectonic processes concentrated at the sharp bending of the Carpathians Arc in the Vrancea region. Considered as a last stage of subduction, the region is characterized by an unusual strain rate per volume at subcrustal depths. The general tectonic frame is a continental collision between pre-alpine platforms and alpine orogen units: western margin of the East European Platform (Moldavian Platform), Scythian and Moesian Platforms, Eastern, Southern and Western (Apuseni Mountains) Carpathians, North Dobrogean orogeny Transylvanian Depression and Eastern margin of the Pannonian Depression Ithe reader is referred to Figure 3 of Bala et al., 2015I. The post-collision deformation at present manifests by rapid deformation in the mantle beneath Vrancea transferred preferentially toward the extra-Carpathians area where transcurrent and normal faulting is recorded along a system of major crustal fractures oriented SE-NW. At the same time, the platform areas are overlapped by the external units of the Carpathian Orogen, resulting in the sinking of basement and fracturing the crust along alignments parallel to the Carpathian Arc (Bala et al. 2015). This tectonic system explains the moderate seismicity spread in front of the Carpathians Arc bend.

Other seismicity activity is observed along the Southern Carpathians down to the Danube River. The contact between the Moesian Platform and Carpathians orogen generates small-to-moderate crustal earthquakes as a consequence of large-scale transcurrent deformation recorded during the Tertiary drift of the tectonic units in Transylvania into the Carpathians embayment by the rapid roll-back of the slab attached to the European continent in the Vrancea region. The clockwise rotation of the upper Carpathians units with respect to Moesia is accommodated through a system of faults crossing NE-SW the Danubian region. Some enhancement of seismic activity is recorded along the contact between the Western Carpathians and the Pannonian Depression, clustered in Banat and Crişana-Maramureş zones. The backarc region (Transylvanian Depression) has weaker seismicity potential. The entire earthquake activity is

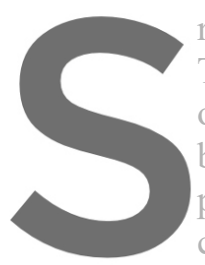
restricted to historical events, and apparentiy is not
The Vrancea subcrustal seismic source located at th
of Romania is a region of concentrated intermediate
boundaries (Ismail-Zadeh et al. 2012). Frohlieh (20
particularly unusual or uncommon since the seismic
concentrated in an area of roughly $30 \times 70 \mathrm{~km}^{2}$ and s
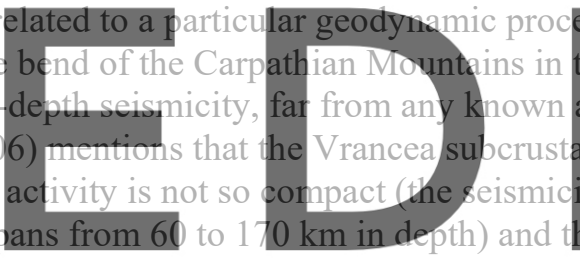
activity is not completely isolated from other seismic regions (one can notice from Figure 1 that there are occurred in October 6, $1908\left(M_{W}=7.1, h=125 \mathrm{~km}\right)$, November 10, $1940\left(M_{W}=7.7, h=150 \mathrm{~km}\right)$, March 4, $1977\left(M_{W}=7.4, h=94 \mathrm{~km}\right)$ and August 30, $1986\left(M_{W}=7.1, h=131 \mathrm{~km}\right)$. In addition, Wenzel et al. (1999) note that the seismic moment release of the Vrancea seismic source is of the same order of magnitude as that of Southern California.

The most important crustal seismic events that affected the territory of Romania were the two earthquakes in Bulgaria in 1901 (Shabla seismic region, $M_{w} \approx 7.2$ ) and 1913 (Gorna seismic region, $M_{w} \approx 7.0$ ), the Fagaras earthquake of $1916\left(M_{w} \approx 6.4-6.5\right)$, as well as the 1991 Banat and Danubius earthquakes (three seismic events with $M_{w} \geq 5.5$ ). Recently, in November 2014, an earthquake of $M_{w}=5.6$ occurred at a focal depth of $40 \mathrm{~km}$ in the Vrancea crustal seismic zone. A horizontal recording obtained during this event in the epicentral region had a peak ground acceleration $(P G A)$ of $0.27 \mathrm{~g}$, which represents one of the largest $P G A s$ ever recorded in Romania.

For Romania, we considered the ROMPLUS catalogue (Oncescu et al., 1999; updated version on http://www.infp.ro/catalog-seismic) revised in agreement with the SHEEC catalogue produced by the SHARE Project. Seismic sources in the neighbouring countries with possible impact in Romania are considered, as well. The Serbian source is defined taking into account the known fault distribution and the epicentres of events as reported in the SHARE catalogue (Stucchi et al. 2013). Sources in north-eastern Bulgaria are defined following Simeonova et al. (2006).

The positions of the earthquakes from the ROMPLUS seismic catalogue and their corresponding magnitudes are shown in Figures 2 and 3 for the 13 crustal seismic sources and for the Vrancea subcrustal seismic source, respectively. 
The ROMPLUS catalogue contains 6322 seismic events that occurred in Romania or neighbouring countries in the period $984-2015$. The histograms of magnitude, focal depth and the evolution of the number of earthquakes in the catalogue with time is given in Figure 4. Declustering was performed using the Gardner and Knopoff (1974) algorithm with the original window parameters. However, special attention was given to the declustering of the catalogue for the Vrancea subcrustal seismic source, since there are many cases of doublet and even triplet earthquakes with small differences in magnitude occurring in this region (triplet earthquakes in 1893 and 1945, doublet earthquakes in 1894, 1896 and 1990).

The input parameters for each seismic source are:

- the coordinates defining the polygon of the source zone;

- magnitude of completeness $M_{C}$;

- maximum magnitude $M_{\max }$;

- activity rates and frequency-magnitude distribution; and

- hypocentral depth distribution.

Assessing the magnitude of completeness $M_{\mathrm{C}}$ for the catalogue of each source is an essential and compulsory step for seismicity analysis. The completeness magnitude $M_{\mathrm{C}}$ is theoretically defined as the lowest magnitude at which $100 \%$ of the earthquakes in a space-time volume are detected (Rydelek and Sachs, 1989). $M_{\mathrm{C}}$ is often estimated by fitting a Gutenberg-Richter model to the observed frequencymagnitude distribution. In this study the Maximum Curvature technique (Wiemer and Wyss, 2000) is applied in order to assess the magnitude of completeness for each earthquake catalogue used in the PSHA.

The magnitude of the maximum considered earthquake, $M_{\max }$, is defined such that, for a given seismic

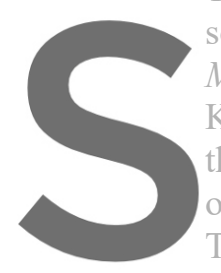
source, no earthquakes witt $M_{\max }$, which is free from su Kijko (2004); this approach threshold magnitude has of seismic hazard. Three focal depths $(10 \mathrm{~km}, 15 \mathrm{~km}$ and $20 \mathrm{~km}$ with equal weight
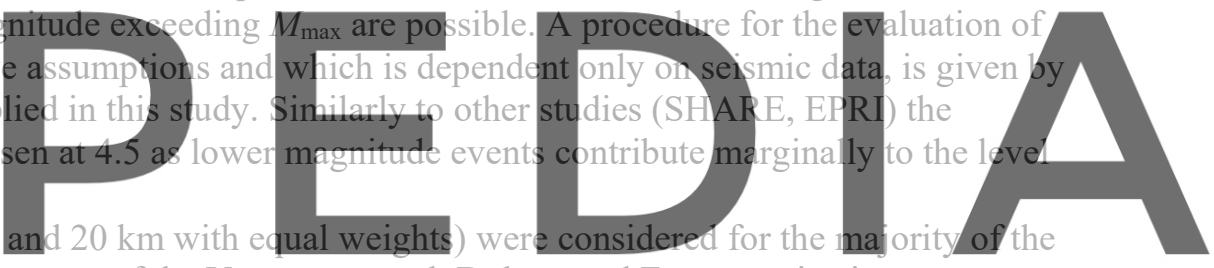
crustal seismic sources, while in the case of the Vrancea crustal, Dulovo and Fagaras seismic sources

the seismicity of the $\mathrm{XX}^{\text {th }}$ century; this model takes into account the concentration of seismic activity in the depth range $90-150 \mathrm{~km}$. The depth ranges for the four layers are: $60-90 \mathrm{~km}, 90-120 \mathrm{~km}, 120-150$ $\mathrm{km}$ and $150-180 \mathrm{~km}$. Only seven earthquakes (all with $M_{W} \leq 4.1$ ) with focal depths larger than $180 \mathrm{~km}$ appear in the ROMPLUS catalogue and as such the seismic activity below $180 \mathrm{~km}$ was not considered in the analysis. The Vrancea subcrustal source has quite limited horizontal dimensions and is well-defined and hence considering a horizontal spatial variation of seismicity within each layer is not important for the computation of seismic hazard over the entire country.

The number of earthquakes (earthquakes with magnitudes larger than $M_{C}$ ) in each seismic catalogue is given in Table 1. The $a$ and $b$ parameters of the Gutenberg-Richter relations are obtained for all the seismic sources through a maximum-likelihood method (McGuire. 2004). The magnitude of completeness (or the minimum considered magnitude) $M_{\min }$, the maximum magnitude $M_{\max }$, the $b$ parameters and its corresponding standard deviation, as well as the mean annual rate of earthquakes exceeding $M_{\min }$ (denoted as $\lambda_{\text {Mmin }}$ ) are given in Table 1 for each seismic source. The comparison between the observed seismicity and the fitted Gutenberg-Richter law is shown in Figure 5 for all the seismic sources used in this study.

\section{Ground-motion models}

The ground-motion models used for the PSHA were selected based on several recent studies (Vacareanu et al. 2013; Pavel et al. 2014a; Pavel et al. 2014b) that dealt with the testing and grading of candidate 
Pure and Applied Geophysics, 173, 2016, 1881-1905

ground motion prediction equations (GMPEs) both for the Vrancea intermediate-depth seismic source and for the crustal seismic sources.

In the afore-mentioned studies, the candidate ground-motion models were tested using the goodness-of-fit measures proposed in Scherbaum et al. (2004), Scherbaum et al. (2009) and Kale and Akkar (2013). The ground-motion database employed for the evaluation of candidate GMPEs (Pavel et al. 2014b) consisted of 431 recordings from 10 intermediate-depth Vrancea earthquakes and 125 recordings from 25 crustal earthquakes. Only subcrustal seismic events with $M_{W}>5.0$ were included in the database since smaller earthquakes have relatively minor structural effects. From the observations made in Romania up to now, earthquakes with $M_{W}<5.0$ have no impact whatsoever on buildings or structures, except that they cause a certain degree of panic. In addition, some of the GMPEs used in the proposed PSHA model should strictly only be applied to earthquakes with $M_{W}>5.0$. Including smaller earthquakes in the seismic hazard assessment for Romania would have a very limited impact on the design ground motions hence their inclusion is not necessary and, because some of the GMPEs do not strictly apply below $M_{w}=5$, extrapolation to much lower magnitudes is not justified.

All the analysed strong ground motions were collected for the BIGSEES project and were recorded mainly by three seismic networks: INCERC (Building Research Institute), INFP (National Institute of Earth Physics) and CNRRS (former National Centre for Seismic Risk Reduction, currently Research Centre for Seismic Risk Assessment). As mentioned in the previous chapter, a normal-faulting earthquake with $M_{w}=5.6$ occurred at a focal depth of $40 \mathrm{~km}$ in the Vrancea crustal seismic zone in November 2014 . 39 pairs of horizontal recordings recorded at source-to-site distances smaller than $200 \mathrm{~km}$ were also added to the ground-motion database used for the evaluation of crustal GMPEs from this event. The detailed procedure for testing as well as a description of the ground-motion database and the detailed results can

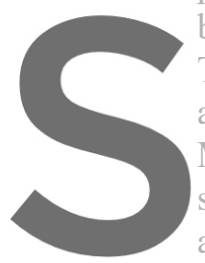
The testing of the groundand east of the Carpathia Mountains) defined with sources. The separation attenuation of seismic wav
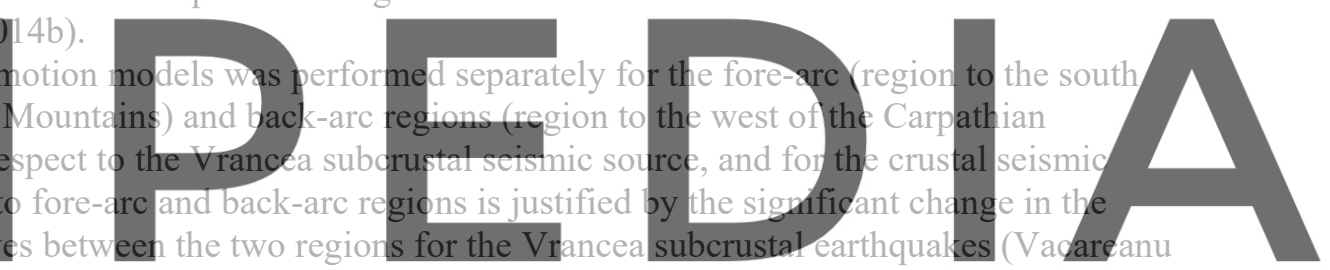

et al. 2015). The position of the earthquakes with ground-motion recordings used in the testing procedure

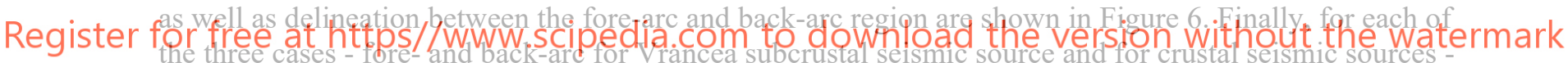

, based on the results of the evaluation procedure we selected three ground-motion models. The testing procedure applied has provided us with weighing factors for each candidate GMIPE. In addition to the ground motion models graded in Pavel et al. (2014b) two additional models were tested using the same ground-motion database, namely the BCHydro model (Abrahamson et al. 2015) for the Vrancea subcrustal seismic source and the Ambraseys et al. (2005) model for crustal earthquakes. The GMPEs which best fit the available ground-motion database are the following:

- Vrancea fore-arc: Vacareanu et al. (2015) - VEA15, BCHydro model (Abrahamson et al. 2015) BCH15 and Youngs et al. (1997) - YEA97;

- Vrancea back-arc: Vacareanu et al. (2015) - VEA15, BCHydro model (Abrahamson et al. 2015) - BCH15 and Atkinson and Boore (2003) - AB03; and

- Crustal - Cauzzi and Faccioli (2008) - CF08, Ambraseys et al. (2005) - AEA05 and Akkar and Bommer (2010) - AB10.

Table 2 shows the values of several goodness-of-fit parameters proposed in Scherbaum et al. (2004), Scherbaum et al. (2009) and Kale and Akkar (2013) for the three best-fitting models. The parameters are the following: median of the likelihood $L H-M E D L H$, the mean (MEANNR), median (MEDNR) and standard deviation (STDNR) of the normalized residuals and the $E D R$, the Euclidean distance ratio (Kale and Akkar, 2013).

The final weighing scheme is given in Table 3. The weighting factors corresponding to each groundmotion model are based on the values of the goodness-of-fit parameters shown in Table 2, as well as on 
the distribution of the inter- and intra-event residuals (Pavel et al. 2014b). The attenuation with epicentral distance of the median amplitudes of the ground-motion models used in PSHA is shown in Figure 7. The selected GMPEs require input parameters that are readily available for Romanian data. For the same reason, other state-of-the-art ground-motion models were not selected for analyses. Parameters like depthto-top of rupture $\left(Z_{T o r}\right)$, down-dip rupture width $(W)$, average shear-wave velocity over the top $30 \mathrm{~m}$ of subsurface $\left(V_{s, 30}\right)$ and the depth to $V_{s}=1.0 \mathrm{~km} / \mathrm{s}$ or $2.5 \mathrm{~km} / \mathrm{s}\left(Z_{1.0}\right.$ and $\left.Z_{2.5}\right)$ could not be computed because the data needed for their estimation (Kaklamanos et al. 2011) are not available at this moment.

\section{Seismic-hazard analysis and results}

The seismic-hazard model developed in the current study and based on the Cornell-McGuire approach will be called hereinafter the BIGSEES model. The main advantages of this model with respect to the other models previously used for PSHA for Romania (some of which are mentioned in Chapter 1) are:

- Updated contours and catalogues for seismic sources affecting Romania territory;

- Selection of GMPEs used in the analysis is based on rigorous testing and grading procedures from the literature;

- Consideration of epistemic uncertainties through a logic tree approach; and Quantification of the overall uncertainties (as shown subsequently in the paper).

A logic tree (Kulkarni et al. 1984; Coppersmith and Youngs 1986; Bommer et al. 2005; Bommer and Scherbaum, 2008) is used for the computation of the seismic hazard. The branches of the logic tree represent alternative models or values of the parameters considered in the analysis. The epistemic uncertainties are expressed as branch weights representing the degree of confidence of the experts/analysts in the appl cability 0 branches. Finally, the PS subcrustal seismic source The logic tree used for the ground-motion models, Figure 6 are not "true" branches. Ace focal depth or various GMPEs. The true purpose of Fig. 6 is to show in a simple manner the different

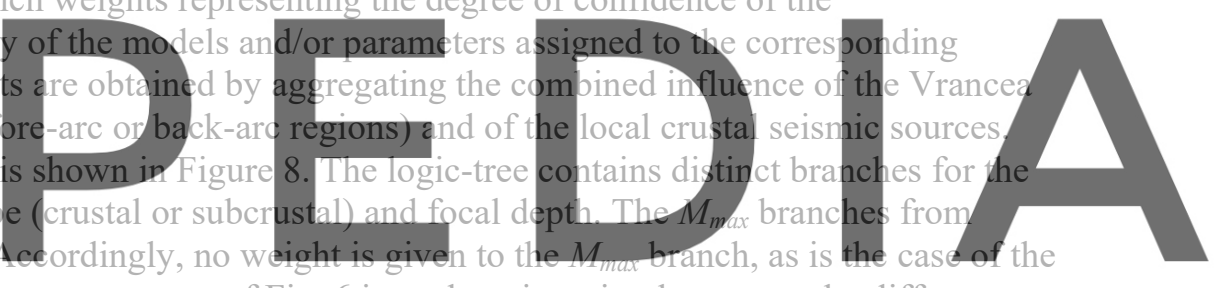

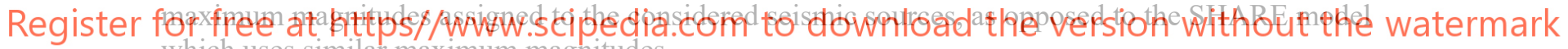
which uses similar maximum magnitudes.

A uniform distribution of probability was assumed for the maximum magnitude $M_{\max }$ corresponding to each seismic zone ( \pm 0.3 degrees of magnitude, similarly to the SHARE model). Moreover, uncertainty in the parameter $b$ of the Gutenberg-Richter relation obtained through computations performed on the individual seismic catalogues is also taken into account in the analysis through the use of its standard deviation. The computations were performed using the 2014 version of the CRISIS code (Ordaz et al. 2013). In the CRISIS software, $b$ parameter is considered as an independent random variable modelled using the gamma probability distribution. The truncation level for the standard deviation of the groundmotion models is taken as 2.5. The computations were performed on a grid of $0.1^{\circ} \times 0.1^{\circ}$ that covers the entire territory of Romania. The soil conditions assigned for the sites where the computations were performed were inferred from a map based on the topographic slope method proposed by Wald and Allen (2007). This method represents, of course, a quite rough method for the evaluation of soil conditions and it was used due to the lack of more accurate data at the national level. An evaluation of the applicability of the topographic slope method for Europe showed that it is applicable for studies covering a large geographical area (Lemoine et al. 2012).

The mean seismic hazard map covering all the soil conditions for the expected geometric mean of the two horizontal components of $P G A$ with a return period of 475 years obtained in this study is shown in Figure 9. On Figure 9 the high $P G A$ s in the epicentral region of Vrancea subcrustal earthquakes are noteworthy. The reason for providing a map that covers all the soil classes present in the country is related to the seismic design code of Romania, which uses such an approach. The project that funded our research 
(BIGSEES project) requested such a map that could be used in the future for the seismic design of earthquake-resistant structures.

The mean hazard curves for the ten most populous cities in Romania according to the 2011 census are shown in Figure 10. Douglas et al. (2014) compare the results of different seismic hazard studies by computing the associated uncertainty levels for two spectral periods and for two mean return periods. The mean, median, 5th and 95th percentile PGAs (common to both the SHARE and BIGSEES hazard models), as well as the corresponding uncertainty levels for the 20 most populous cities in Romania (shown in Figure 5) for a return period of 475 years are shown in Figure 11. The uncertainty is computed with a similar relation as that proposed in Douglas et al. (2014), namely $100 \cdot \log \left(P G A_{95} / P G A_{5}\right)$, where $P G A_{95}$ and $P G A_{5}$ are the $P G A$ s corresponding to the 95th and 5th percentiles. The results show that the largest differences between the mean and the median, as well as the largest uncertainties, are encountered for the cities in the western part of Romania (e.g. Arad, Cluj-Napoca, Oradea, Satu-Mare and Targu Mures), which are mainly under the influence of local crustal seismic sources. In the case of the cities situated in the eastern and southern part of Romania (e.g. Bacau, Braila, Bucharest, Buzau, Galati and Pitesti), the uncertainty is much diminished and moreover the median and mean hazard levels are closely spaced.

\section{Evaluation of the results and discussions}

In thís section, the seismic hazard results are assessed and compared with the results obtained in the SHARE project (http://www.efehr.org:8080/jetspeed/portal/hazard.psml). A direct comparison of the seismic hazard results obtained in BIGSEES and SHARE research projects is not possible since the soil

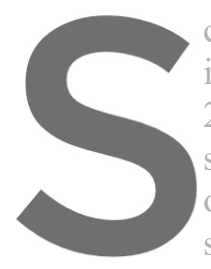
conditions considered are indirect comparisons are $\mathrm{h}$ 200 sites in Romania which seismic hazard curves $(k$ par of the seismic hazard for return periods in the range space) as shown in Vanzi et al. (2015). different-actual soil class
ighlighted in the following.
h cover the entire territory
arameter) for PGA was co
eturn periods in the range
et $a l$. (2015). Based on the
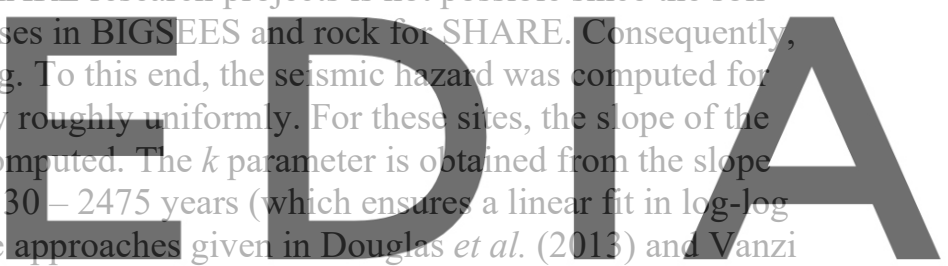
et al. (2015), the annual probability of structural failure, $P_{f s t}$ is computed for the 200 selected sites. The period of 475 years and a lognormal standard deviation of 0.50 (Douglas et al. 2013), is convolved with the hazard curve. The slope and the intercept of the linear fit are then used to compute the probability distribution function of the ground motion parameter (in this case, $P G A$ ). Structural failure is associated with the exceedance of the ultimate limit state as defined in Eurocode 8 (2004) (different from the collapse limit state). The results obtained with the BIGSEES seismic hazard model for the 200 sites are shown in the maps on Figure 12 (uncertainty level, $k$ value and corresponding mean return period of structural failure). It is noticeable from Figure 12 that the lowest level of uncertainty and the largest values of $k$ (corresponding to the lowest return periods of structural failure) are encountered for the sites situated in the southern and eastern part of Romania, which are under the dominant influence of the Vrancea subcrustal seismic source. The lower $k$ values are attributed to sites in the central and western part of Romania, where local crustal seismic sources dominate.

The SHARE model for Romania (http://www.efehr.org:8080/jetspeed/portal/hazard.psml) is based on area sources covering the entire territory. The truncation level used for the variability of ground motions in SHARE project is 3.0 standard deviations, while the soil conditions for all sites were taken as rock. Four ground-motion models were used for the active shallow crust sources in the SHARE project, with the largest weights given to the Cauzzi and Faccioli (2008) and Akkar and Bommer (2010) relations. In the case of the Vrancea subcrustal seismic source, two ground motion prediction equations were selected, namely Youngs et al. (1997) with a weight of 0.40 and Lin and Lee (2008) with a weight of 0.60. We are not aware of the reasons for which in the SHARE project only two of the ground-motion models proposed by Delavaud et al. (2012) were finally selected for the Vrancea subcrustal seismic source. The ground- 
motion model of Youngs et al. (1997) provides the best fit to the database of ground motions from Vrancea earthquakes, as shown in several studies (e.g. Vacareanu et al. 2013; Pavel et al. 2014a; Pavel et al. 2014b). Whereas, the GMPE of Lin and Lee (2008) does not fit well the available ground-motion database, as shown in the same studies, and its predicted median amplitude underestimates the observed ground motions. Moreover, this ground-motion model (for intraslab earthquakes) was developed using ground motions recorded during seismic events with magnitudes $M_{W} \leq 6.6$ (intraslab earthquakes) and its applicability to larger magnitude seismic events is questionable. Another observation related to the two ground-motion models used in SHARE can be noticed from Figure 13: the PGAs derived from the model of Youngs et al. (1997) are larger for soil than for rock conditions, while in the case of the Lin and Lee model (2008) it is exactly the opposite $\left(P G A_{\text {rock }}>P G A_{\text {soil }}\right)$. The computations in Figure 13 are for an earthquake of $M_{W}=7.4$ and focal depth $h=94 \mathrm{~km}$, similar to the Vrancea 1977 seismic event. The ratio of the $P G A$ s with a mean return period of 475 years computed in this study and the results from SHARE (at the bedrock level) are shown in Figure 14. The values for the SHARE model were obtained from the seismic hazard curves given at http://www.efehr.org:8080/jetspeed/portal/hazard.psml.

One can notice that the differences between the PGAs from the two studies are larger than 50\% for most of the territory of Romania, especially in southern and eastern Romania, which are under the influence of the Vrancea subcrustal seismic source. Some of the difference is attributable to the different soil conditions considered in the studies (soil vs. rock). Nevertheless, the differences between PGAs with an exceedance probability of $10 \%$ in 50 years obtained in the two hazard models are larger than the soil factors proposed in Eurocode 8 (2004) or by Pitilakis et al. (2012) (albeit over 50\% of the ratios obtained fall in the domain $0.8-1.2$ if one applies the soil factors proposed by Pitilakis et al. 2012). Another reason for the differences encountered between the two seismic hazard models (BIGSEES and SHARE)

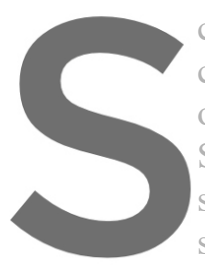
can be attributed to the seismicity parameters of the
comparison is provided between the fitted Gutenber
observed seismicity rates in the XX $X^{\text {th }}$ century. One ca
SHARE model underestimates the observed seismic
subcrustal seismic source using four regions with dif
stretches from the Repullic of Moldova to Bulgaria
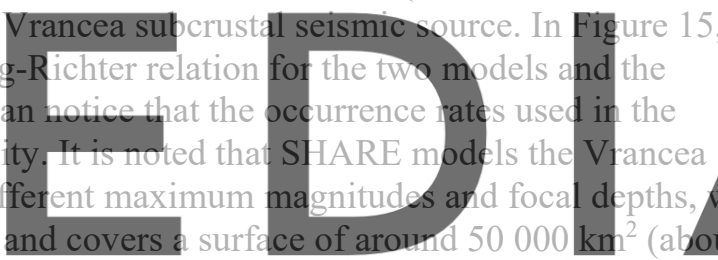

one-fifth of the surface of Romania) (see Figure 14 in Woessner et al. 2015). This seismic region, which

is quite well constrained by many studies in the literature.

The relation between the $k$ parameter (slope of the seismic hazard curve for $P G A$ ) is shown for the 200 sites in Figure 16 for both the SHARE and the BIGSEES models. A linear trend is inferred from both plots; however, the $k$ values of the BIGSEES model cover a much broader range $(1.3-3.0)$ compared to the values derived from the SHARE model, which are in the range $1.2-2.5$. Nevertheless, in both cases the failure probability $P_{f}$ increases almost linearly with the slope of the seismic hazard curve $k$. The $k$ values obtained from both models are plotted on the same graph in Figure 17 revealing a somewhat linear increasing trend, as revealed by the fitted trendline (although the trend is not too well constrained by data due to increased variability of the results).

An exponential relation between the parameter $k$ and the ratio of $P G A$ s for return periods of 475 and 225 years is inferred from Figure 18 for both seismic hazard models (BIGSEES and SHARE). A $k$ value of 3 is recommended in Eurocode 8 (2004) and this leads to a ratio of the $P G A$ s for mean return periods of 475 and 225 years of around 1.25. In the case of lower $k$ values this ratio can be as high as 1.70 . Larger $k$ values lead to lower ratios between the $P G A$ s with exceedance probabilities of $20 \%$ and $10 \%$ in 50 years, while for smaller $k$ values the opposite trend holds true.

The $P G A$ for an annual failure probability $P_{f}=2 \times 10^{-4}$ is computed, as proposed in Luco et al. (2007). The ratio of the $P G A$ for an annual failure probability $P_{f}=2 \times 10^{-4}$ to the $P G A$ with $10 \%$ exceedance probability in 50 years is similar for both seismic hazard models: mean $=2.61$ and standard deviation $=$ 0.19 for the SHARE model and mean $=2.67$ and standard deviation $=0.14$ for the BIGSEES model. 
Two recent papers, namely Weatherhill and Danciu (2014) and Silva et al. (2014), assess some of the results obtained in the SHARE project and further develop them to compute some of the parameters describing the design spectrum of Eurocode 8 (2004) and to derive risk-targeted maps for Europe. The results for Romania, shown in the two afore-mentioned references, are debatable for the following two related issues:

- the $k$ values for Romania (and for $P G A$ ) are larger than 2.5, with pockets in which $k$ reaches the maximum value anywhere in Europe $(k=4.5)$ (Weatherhill and Danciu, 2014). These pockets of large $k$ values do not correspond to any seismic source used in the SHARE hazard model. Even though the map of $k$ values shown in Weatherhill and Danciu (2014) resembles the map displayed in Figure 19, there are significant differences in the $k$ values; and

- the annual collapse probability is amongst the smallest in Europe, with most of the territory of Romania having assigned an annual failure probability in the range $10^{-5}-10^{-6}$.

Because the annual probability of failure should have a strong positive correlation on $k$, these results are in our opinion contradictory.

Moreover, there is a need to further discuss the results obtained using the two seismic hazard models (SHARE and BIGSEES) in the light of the building provisions of the Romanian seismic design code P100-1/2013 (2013) and its previous two versions. For instance, the seismic hazard level for Bucharest has increased from a value of $P G A$ of $0.20 \mathrm{~g}$ (period $1978-2006$ ), to $0.24 \mathrm{~g}$ (period 2007 - 2013) and up to $0.30 \mathrm{~g}$ (present level) for mean return periods of 50 years, 100 years and, respectively, 225 years. In the case of Focsani, the seismic hazard level has increased from $0.28 \mathrm{~g}$ to $0.40 \mathrm{~g}$ in the current version of the seismic code. Consequently, people unfamiliar with the field of seismic hazard might falsely consider, based on the maps given in Weatherhill and Danciu (2014) and Silva et al. (2014), that the provisions of

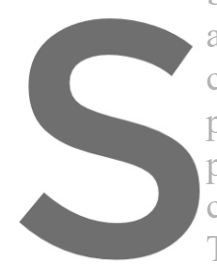
all the Romanian seismi cross-sections. There is a project is for rock conditio particularly in most of the cannot be applied without The $k$ value and its methoc codes in the
strong nee
ons, which
southern
proper site-
d of compu he past $30-40$ y
ed to emphasize t
h might only occu
and eastern Rom
te-dependent soil
putation, in partic
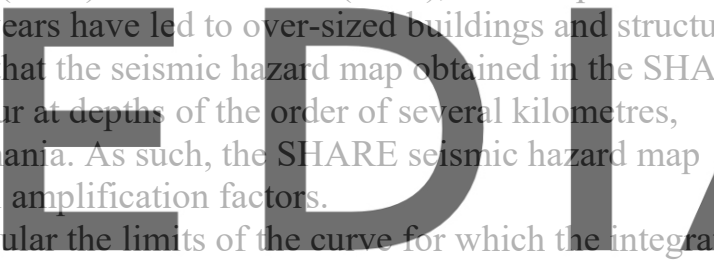

is performed have a great impact on the computed failure probability. Figure 20 shows such an example

to 2.10 ) is determined from the $P G A$ range $0.05 \mathrm{~g}-0.40 \mathrm{~g}$. The fitted lines have slopes that vary by a factor of two; hence, it is crucial to select the correct range in which the seismic hazard curve can be approximated by a straight line. For instance, the $k$ value of 2.10 approximates the curve for mean return periods between $25-2200$ years very well, which represent the domain of interest for current seismic codes. The other two $k$ values, which are determined based on a much broader range of $P G A \mathrm{~s}$, do not closely match the hazard curve, especially in the region of engineering interest.

\section{Summary and conclusions}

The analysis of the results obtained for the $P G A$ with an exceedance probability of $10 \%$ in 50 years, and the comparison with the results obtained in the pan-European SHARE project, highlights the following important issues:

- There are considerable differences between the results obtained using the two seismic hazard models (BIGSEES and SHARE), especially for the region in southern and eastern Romania that is under the dominant influence of the Vrancea subcrustal seismic source. This study has obtained results close to the ones computed by Sokolov et al. (2009). However, one has to consider that Sokolov et al. (2009) used only one ground motion model (namely, Ambraseys et al. 1996) for the crustal seismic source, while for the Vrancea seismic source, they use only two GMPEs (the azimuth-dependent model developed by Sokolov et al. 2008 for the Vrancea subcrustal seismic source and the model of Lungu et al. 2000 which can be used only for $P G A$ ). From the point of 
view of the values, the $P G A$ s with $10 \%$ exceedance probability in 50 years obtained for Bucharest and Focsani are slightly larger in the BIGSEES model (around 10\%) as compared to the Sokolov et al. (2009) model.

- The seismicity of the sources affecting the Romanian territory is different in the two models:

- the SHARE models includes seismic sources covering the entire territory of Romania, with similar minimum and maximum magnitudes, while the BIGSEES model uses concentrated seismic sources with similar minimum magnitudes and different maximum magnitudes. The occurrence rates are computed in a similar manner for both models, albeit in the case of the SHARE model the seismicity is distributed over a much larger area;

- The SHARE model defines the Vrancea subcrustal seismic source as having an area of around $50000 \mathrm{~km}^{2}$ in order to model a likely azimuth-dependent pattern of ground-motion amplitudes. Thus, there are four zones of different focal depths, maximum magnitudes and seismicity parameters that cover an area roughly ten times the zone in which intermediatedepth seismicity was observed in Vrancea. In the BIGSEES model, the Vrancea subcrustal seismic source is confined to an area of about $5000 \mathrm{~km}^{2}$ and the azimuth-dependent attenuation is only related to the regions in front of the Carpathian Mountains (fore-arc region) and behind the Carpathian Mountains (back-arc region). The map in Figure 21, which is based mainly on the work of Marmureanu (2015), shows how often 83 monasteries in Romania were damaged (once or several times) during large magnitude $\left(M_{W}>7.4\right)$ Vrancea earthquakes that occurred in the past 200 years (in 1802, 1838, 1940 and 1977). Four means that all the four earthquakes (in 1802, 1838, 1940 and 1977) damaged the monastery, three

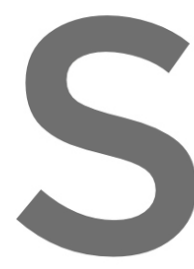
means that the monastery was damaged by three of the four seismic events and so on. The first interesting observation is that the monasteries clamaged by earthquakes are st tuated in a area containing half of eastern Romania and most of the southern part. However, if we looly the monasteries damaged once, the area is roughily equal to $60 \%$ of the territory o We can find monasteries situated at over $300 \mathrm{~km}$ from the earthquakes that were damaged either in interesting observation is that the monas 1802

adjacent to the Black Sea) were all damaged by the same Vrancea seismic event - the 1940

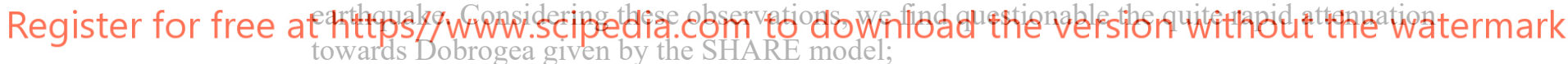

- Two ground-motion models (Youngs et al. 1997; Lin and Lee, 2008) were selected for the

Vrancea subcrustal seismic source in the SHARE model, but recent testing using ground motions recorded during Vrancea intermediate-depth earthquakes has shown that the Lin and Lee (2008) GMPE underestimates the ground-motion amplitudes. Moreover, one has to take into account that the Lin and Lee model (2008) was derived from ground motions recorded during earthquakes with $M_{W} \leq 6.6$ (for intraslab earthquakes).

- The earthquake occurrence rates for the Vrancea subcrustal seismic source used in the SHARE model appear to underestimate the observed seismic activity for the $\mathrm{XX}^{\text {th }}$ century.

- There is a linear trend between the slope of the seismic hazard curve ( $k$ value) and the associated annual failure probability, as highlighted by the results obtained for 200 sites in Romania.

- The uncertainty associated with the seismic hazard results has different patterns for the two hazard models: in the BIGSEES model, the uncertainty is larger for sites under the influence of local crustal seismic sources and smaller for the sites under the influence of the Vrancea subcrustal seismic source, while in the SHARE model the uncertainty is more uniform across Romania.

- The limits of the seismic hazard curve between which the power function is fitted have a great impact on the associated $k$ values and on the corresponding structural failure probability. Based on these findings we noticed that the map shown in Silva et al. (2014) contains some questionable 
results since Romania has neither the lowest seismic hazard in Europe nor the most over- or under--sized structures.

In summary, we consider that in the light of the recent seismic hazard studies performed for Romania, more discussions and clarifications are needed to obtain a future map that reflects accurately the seismic hazard of Romania, and which can be used in a possible future pan-European seismic hazard map. Moreover, if one aims at converting a seismic hazard zonation map into a design tool for a compulsory seismic code, the map must provide a well-balanced scientifically sound target level of safety for new structures.

\section{Acknowledgements}

The results presented in this paper are obtained within the BIGSEES Project financed by the Romanian Ministry of Education and Scientific Research (MECS) under Grant Number 72/2012. This support is gratefully acknowledged. Authors would like to thank Prof. M. Ordaz (Instituto de Ingenieria, UNAM, México) for providing the CRISIS 2014 software. The constructive comments from two anonymous reviewers are greatly appreciated as they have helped us to improve considerably the quality of the manuscript.

\section{References}

1. Abrahamson, N.A., Gregor, N., and Addo, K. (2015), BC Hydro ground motion prediction equations for subduction earthquakes, Eq Spectra, doi: 10.1193/051712EQS188MR.

2. Ambraseys, N.N., Simpson, K.A., and Bommer, J.J. (1996), Prediction of horizontal response spectra in Europe, Eq. Eng. Struct. Dyn., 25, 371-400.

3. Ambraseys, N.N., Douglas, J., Sarma, S.K., and Smit, P.M. (2005), Equations for the estimation of strong ground motions from shallow crustal earthquakes using data from Europe and the Middle East: horizontal peak ground acceleration and spectral acceleration, Bull. Eq. Eng., 3, 1-53.

4. Akkar, S., and Bommer, J.J. (2010), Empirical equations for the prediction of $P G A$, PGV and spectral accelerations in Europe, the Mediterranean and the Middle East, Seismol. Res. Lett., 81(2), 95-206.

5. Atkinson, G., and Boore, D. (2003), Empirical ground-motion relations for subduction-zone earthquakes and their application to Cascadia and other regions, Bull. Seismol. Soc. Am., 93(4), 1703-1729.

6. Bala, A., Raileanu, V., Dinu, C., and Diaconescu, M. (2015), Crustal seismicity and active fault systems in Romania, Rom. Rep. Phys., 67(3), 1176-1191.

7. Basili, R., Kastelic, V., Valensise, G., and DISS Working Group (2009). DISS3 tutorial series: Guidelines for compiling records of the Database of Individual Seismogenic Sources, version 3, INGV Technical Report 108.

8. Bommer, J.J., Scherbaum, F., Bungum, H., Cotton, F., Sabetta, F., and Abrahamson, N.A. (2005), On the use of logic trees for ground-motion prediction equations in seismic-hazard analysis, Bull. Seismol. Soc. Am., 95, 377-389.

9. Bommer, J.J., and Scherbaum, F. (2008), The use and misuse of logic-trees in probabilistic seismic hazard analysis, Eq. Spectra 24, 997-1009.

10. Cauzzi, C., and Faccioli, E. (2008), Broadband (0.05 to $20 \mathrm{~s})$ prediction of displacement response spectra based on worldwide digital records, J. Seismol., 12(4), 453-475.

11. Cornell, C.A. (1968), Engineering seismic analysis, Bull. Seismol. Soc. Am. 58, 1583 - 1606.

12. Coppersmith, K.J., and Youngs R.R. (1986), Capturing uncertainty in probabilistic seismic hazard assessments within intraplate environments. In: Proceedings of the Third U.S. National Conference on Earthquake Engineering, August 24-28, 1986, Charleston, U.S.A, Earthquake Engineering Research Institute, El Cerrito CA U.S.A., vol. 1, pp 301-312. 
13. Delavaud, E., Cotton, F., Akkar, S., Scherbaum, F., Danciu, L., Beauval, C., Drouet, S., Douglas, J., Basili, R., Sandikkaya, A., Segou, M., Faccioli, E., and Theodoulidis, N. (2012), Toward a groundmotion logic tree for probabilistic seismic hazard assessment in Europe, J Seismol., 16(3), 451-473.

14. Douglas, J., Ulrich, T., and Negulescu, C. (2013), Risk-targeted seismic design maps for mainland France, Nat. Haz., 65, 1999-2013.

15. Douglas, J., Ulrich, T., Bertil, D., and Rey, J. (2014), Comparisons of the ranges of uncertainty captured in different seismic-hazard studies, Seismol. Res. Lett., 85, 977-985.

16. EN 1998-1:2004 (2004), Eurocode 8: design of structures for earthquake resistance, Part 1: general rules, seismic actions and rules for buildings, Brussels, CEN.

17. EPRI (2006), Program on Technology Innovation: Use of Cumulative Absolute Velocity (CAV) in Determining Effects of Small Magnitude Earthquakes on Seismic Hazard Analyses, Report No. 1014099, Palo Alto, California.

18. Frohlich, C. (2006), Deep earthquakes, Cambridge, Cambridge University Press.

19. Gardner, J.K., and Knopoff, L. (1974), Is the sequence of earthquakes in southern California, with aftershooks removed, Poissonian?, Bull. Seismol. Soc. Am., 64, 1363-1367.

20. Ismail-Zadeh, A., Matenco, L., Radulian, M., Cloetingh, S., and Panza, G. (2012), Geodynamics and intermediate-depth seismicity in Vrancea (the south-eastern Carpathians): current state-of-the art, Tectonophysics, 530-531, 50-79.

21. Kale, Ö., and Akkar, S. (2013), A new procedure for selecting and ranking ground-motion prediction equations (GMPEs): the Euclidean distance-based ranking (EDR) method, Bull. Seismol. Soc. Am., 103(2A), 1069-1084.

22. Kaklamanos, J., Baise, L.G., and Boore, D.M. (2011), Estimating unknown input parameters when implementing the NGA ground-motion prediction equations in engineering practice, Eq Spectra, 27(4), 1219-1235.

23. Kijko, A. (2004), Estimation of the maximum earthquake magnitude, $m_{\max }$, Pure Appl. Geophys., $161,1655-1681$.

24. Kramer, S. (1996), Geotechnical Earthquake Engineering. New Jersey, Upper Saddle River: Prentice Hall.

25. Kulkarni, R.B., Youngs, R.R., and Coppersmith K.J. (1984), Assessment of confidence intervals for results of seismic hazard analysis. In: Proceedings of the Eighth World Conference on Earthquake Engineering, July 21-28, 1984, San Francisco, U.S.A., Prentice-Hall Inc., Englewood Cliffs NJ U.S.A., Vol 1, pp 263-270.

26. Lemoine, A., Douglas, J., and Cotton, F. (2012), Testing the applicability of correlations between topographic slope and Vs30 for Europe, Bull. Seismol. Soc. Am., 102(6), 2585-2599.

27. Lin, P.S., and Lee, C.T. (2008), Ground-motion attenuation relationships for subduction-zone earthquakes in Northeastern Taiwan, Bull. Seismol. Soc. Am., 98(1), 220-240.

28. Luco, N., Ellingwood, B., Hamburger, R.O., Hooper, J.D., Kimball, J.K., and Kircher, C.A. (2009), Risk-targeted versus currents seismic design maps for the conterminous United States, SEAOC 2007 convention proceedings.

29. Lungu, D., Aldea, A., Arion, C., Demetriu, S., and Cornea, T. (2000), Microzonage Sismique de la ville de Bucarest - Roumanie, Cahier Technique de l'Association Française du Génie Parasismique, 20, 31-63.

30. Lungu, D., Demetriu, S., Aldea, A., and Arion, C. (2006), Probabilistic seismic hazard assessment for Vrancea earthquakes and seismic action in the new seismic code of Romania. Proceedings of the First European Conference on Earthquake Engineering and Seismology, Geneva, paper 1003.

31. Mäntyniemi, P., Marza, V.I., Kijko, A., and Retief, P. (2003), A new probabilistic seismic hazard analysis for the Vrancea (Romania) seismogenic zone, Nat. Hazards, 29, 371-385.

32. Marmureanu, G. (2015), Large Vrancea earthquakes after 1700 (in Romanian), AICPS Review, 1$2,142-151$. 
33. McGuire, R.K. (1976), FORTRAN computer program for seismic risk analysis, U.S. Geological Survey, Open-File Report 76-67.

34. McGuire, R. (2004), Seismic hazard and risk analysis, Earthquake Engineering Research Institute MNO-10.

35. Musson, R.M.W (2000), Generalized seismic hazard maps for the Pannonian Basin using probabilistic methods, Pure Appl. Geophys., 157, 147-169.

36. Oncescu, M.C., Mârza, V.I., Rizescu, M., and Popa, M. (1999), The Romanian earthquake catalogue between 984-1997, In: F. Wenzel, D. Lungu, O. Novak. (Eds.), Vrancea Earthquakes: Tectonics, Hazard and Risk Mitigation, Kluwer Academic Publishers, 43-47.

37. Ordaz, M., Martinelli, F., D’Amico, V., Meletti, C. (2013), CRISIS 2008: a flexible tool to perform probabilistic seismic hazard assessment, Seismol. Res. Lett., 84(3), 495-504.

38. P100-1/2013 (2013), Code for seismic design - Part I - Design prescriptions for buildings, Bucharest, Ministry of Regional Development and Public Administration.

39. Pavel, F., Vacareanu, R., Arion, C., and Neagu, C. (2014a), On the variability of strong ground motions recorded from Vrancea earthquakes, Eq. and Struct., 6(1), 1-18.

40. Pavel, F., Vacareanu, R., Neagu, C., and Arion, C. (2014b), Probabilistic seismic hazard assessment for Romania. Part I: Selection of GMPEs, In: Vacareanu R, Ionescu C, editors. Proceedings of the $5^{\text {th }}$ National Conference on Earthquake Engineering \& $1^{\text {st }}$ National Conference on Earthquake Engineering and Seismology, Bucharest, CONSPRESS, p. 213-220.

41. Pitilakis, K., Riga, E., and Anastasiadis, A. (2012), Design spectra and amplification factors for Eurocode 8, Bull. Earthq. Eng., 10, 1377-1400.

42. Radulian, M., Mandrescu, N., Popescu, E., Utale, A., and Panza, G. (2000), Characterization of Romanian seismic zones, Pure Appl. Geophys., 157, 57-77.

43. Reiter, L. (1990), Earthquake Hazard Analysis: Issues and Insights, New York, Columbia University Press.

44. Rydelek, P.A., and Sacks, I.S. (1989), Testing the completeness of earthquake catalogs and the hypothesis of self-similarity, Nature, 337, 251-253.

45. Scherbaum, F., Cotton F., and Smit, P. (2004), On the use of response spectral-reference data for the selection and ranking of ground-motion models for seismic-hazard analysis in regions of moderate seismicity: the case of rock motion, Bull. Seismol. Soc. Am., 94(6), 2164-2185.

46. Scherbaum, F., Delavaud, E., and Riggelsen, E. (2009), Model selection in seismic hazard analysis: an information theoretic perspective, Bull. Seismol. Soc. Am., 99(6), 3234-3247.

47. Silva, V., Crowley, H., and Bazzurro, P. (2014), Risk-targeted hazard maps for Europe. Proceedings of the $2^{\text {nd }}$ European Conference on Earthquake Engineering and Seismology, Istanbul, paper no. 1649.

48. Simeonova, S.D., Solakov, D.E., Leydecker, G., Bushe, H., Schmitt, T., and Kaiser, D. (2006), Probabilistic seismic hazard map for Bulgaria as a basis for a new building code, Nat. Hazards Earth. Syst. Sci., 6, 881-887.

49. Sokolov, V.Y., Bonjer, K.P., Wenzel, F., Grecu, B., and Radulian, M. (2008), Ground-motion prediction equations for the intermediate depth Vrancea (Romania) earthquakes based on Fourier amplitude spectra. Bull. Eq. Eng., 6(3), 367-388.

50. Sokolov, V.Y., Wenzel, F., and Mohindra, R. (2009), Probabilistic seismic hazard assessment for Romania and sensitivity analysis: a case of joint consideration of intermediate-depth (Vrancea) and shallow (crustal) seismicity, Soil Dyn. Earthq. Eng., 29, 364-381.

51. Stucchi, M., Rovida, A., Gomez Capera, A.A., Alexandre, P., Camelbeeck, T., Demircioglu, M.B., Gasperini, P., Kouskouna, V., Musson, R.M.W., Radulian, M., Sesetyan, K., Vilanova, S., Baumont, D., Bungum, H., Fäh, D., Lenhardt, W., Makropoulos, K., Martinez Solares, J.M., Scotti, O., Živčić, M., Albini, P., Batllo, J., Papaioannou, C., Tatevossian, R., Locati, M., Meletti, C., Viganò, D., and Giardini, D.. (2013), The SHARE European Earthquake Catalogue (SHEEC) 1000-1899, J. Seismol., 17, 523-544. 
52. Vacareanu, R., Pavel, F., and Aldea, A. (2013), On the selection of GMPEs for Vrancea subcrustal seismic source, Bull. Eq. Eng., 11(6), 1867-1884.

53. Vacareanu, R., Lungu, D., Aldea, A., Demetriu, S., Pavel, F., Arion, C., Iancovici, M. and Neagu, C. (2014), Probabilistic seismic hazard assessment for Romania. Part III: seismic hazard maps. In: Vacareanu R, Ionescu C, editors, Proceedings of the $5^{\text {th }}$ National Conference on Earthquake Engineering \& $1^{\text {st }}$ National Conference on Earthquake Engineering and Seismology, Bucharest, CONSPRESS, p. 229-236.

54. Vacareanu, R., Radulian, M., Iancovici, M., Pavel, F., and Neagu, C. (2015), Fore-arc and back-arc ground motion prediction model for Vrancea intermediate depth seismic source, J. Eq. Eng., 19(3), $535-562$.

55. Vanzi, I., Marano, G.C., Monti, G., and Nuti, C. (2015), A synthetic formulation for the Italian seismic hazard anc code implications for the seismic risk, Soil Dyn. Earthq. Eng., 77, 111-122.

56. Wald, D.J., and Allen, T.I. (2007), Topographic slope as a proxy for seismic site conditions and amplification. Bull. Seismol. Soc. Am., 97, 1379-1395.

57. Weatherhill, G., and Danciu, L. (2014), A regional perspective on Eurocode 8 seismic inputs in the context of a harmonised European seismic hazard model, Proceedings of the $2^{\text {nd }}$ European Conference on Earthquake Engineering and Seismology, Istanbul, paper no. 3268.

58. Wenzel, F., Achauer, U., Enescu, D., Kissling, E., Russo, R., Mocanu, V., and Musacchio, G. (1998), Detailed look at final stage of plate break-off is target of study in Romania, EOS Trans. Am. Geophys. Uni., 79(48), 589-600.

59. Wiemer, S., and Wyss, M. (2000), Minimum magnitude of complete reporting in earthquake catalogs: examples from Alaska, the Western United States, and Japan, Bull. Seismol. Soc. Am., 90, 859-869.

60. Woessner, J., Danciu, L., Giardini, D., Crowley, H., Cotton, F., Grünthal, G., Valensise, G., Arvidsson, R., Basili, R., Demircioglu, M.B., Hiemer, S., Meletti, C., Musson, R.M.W., Rovida, A.N., Sesetyan, K., Stucchi, M., and the SHARE Consortium (2015), The 2013 European Seismic Hazard Model: key components and results, Bull. Earthq. Eng., DOI: 10.1007/s10518-015-9795-1

61. Youngs, R.R., Chiou, S.J., Silva, W.J., and Humphrey, J.R. (1997), Strong ground motion attenuation relationships for subduction zone earthquakes, Seismol. Res. Lett., 68(1), 58-73.

62. http://infp.infp.ro/bigsees/default.htm

63. www.share-eu.org

64. http://www.efehr.org:8080/jetspeed/portal/hazard.psml 
Pure and Applied Geophysics, 173, 2016, 1881-1905

Table 1. Seismic sources, seismicity parameters and minimum and maximum magnitudes used in PSHA as well as the number of earthquakes within the catalogue used to assess these parameters.

\begin{tabular}{|c|c|c|c|c|c|c|c|}
\hline \multicolumn{2}{|l|}{ Seismic source } & $\begin{array}{l}\text { Minimum } \\
\text { magnitude, } \\
M_{\min }\end{array}$ & $\begin{array}{l}\text { Maximum } \\
\text { magnitude, } \\
M_{\max }\end{array}$ & $b$ & $\lambda_{\text {Mmin }}$ & $\begin{array}{l}\text { Standard } \\
\text { deviation } \\
\text { of } b\end{array}$ & $\begin{array}{l}\text { No. of } \\
\text { earthquakes }\end{array}$ \\
\hline \multicolumn{2}{|l|}{ Banat } & 4.5 & 6.4 & 1.10 & 0.17 & \pm 0.17 & 57 \\
\hline \multicolumn{2}{|l|}{ Barlad Depression } & 4.5 & 5.8 & 1.07 & 0.07 & \pm 0.42 & 40 \\
\hline \multicolumn{2}{|l|}{ Crisana Maramures } & 4.5 & 6.6 & 0.96 & 0.11 & \pm 0.18 & 57 \\
\hline \multicolumn{2}{|l|}{ Danubius } & 4.5 & 6.0 & 0.40 & 0.14 & \pm 0.10 & 54 \\
\hline \multicolumn{2}{|l|}{ Dulovo } & 4.5 & 6.6 & 0.49 & 0.09 & \pm 0.16 & 21 \\
\hline \multicolumn{2}{|l|}{ Fagaras Campulung } & 4.5 & 6.8 & 0.97 & 0.12 & \pm 0.21 & 31 \\
\hline \multicolumn{2}{|l|}{ Gorna } & 4.5 & 7.4 & 0.57 & 0.13 & \pm 0.20 & 31 \\
\hline \multicolumn{2}{|c|}{ Pre-Dobrogea Depression } & 4.5 & 5.7 & 1.84 & 0.06 & \pm 0.31 & 54 \\
\hline \multicolumn{2}{|l|}{ Serbia } & 4.5 & 6.1 & 1.57 & 0.59 & \pm 0.22 & 122 \\
\hline \multicolumn{2}{|l|}{ Shabla } & 4.5 & 7.8 & 0.73 & 0.11 & \pm 0.20 & 15 \\
\hline \multicolumn{2}{|l|}{ Shumen } & 4.5 & 6.3 & 1.48 & 0.07 & \pm 0.44 & 16 \\
\hline \multicolumn{2}{|l|}{ Transylvania } & 4.5 & 6.2 & 0.52 & 0.03 & \pm 0.24 & 11 \\
\hline \multicolumn{2}{|l|}{ Vrancea crustal } & 4.5 & 6.3 & 1.10 & 0.11 & \pm 0.11 & 40 \\
\hline \multirow{4}{*}{$\begin{array}{l}\text { Vrancea } \\
\text { intermediate-depth }\end{array}$} & $60 \mathrm{~km}-90 \mathrm{~km}$ & 4.9 & 7.0 & 0.20 & 0.16 & \pm 0.20 & \multirow{4}{*}{230} \\
\hline & $90 \mathrm{~km}-120 \mathrm{~km}$ & 4.9 & 8.0 & 0.68 & 0.63 & \pm 0.12 & \\
\hline & $120 \mathrm{~km}-150 \mathrm{~km}$ & 4.9 & 8.1 & 0.87 & 1.20 & \pm 0.08 & \\
\hline & $150 \mathrm{~km}-180 \mathrm{~km}$ & 4.9 & 6.6 & 1.00 & 0.22 & \pm 0.18 & \\
\hline
\end{tabular}


Pure and Applied Geophysics, 173, 2016, 1881-1905

Table 2. Grading parameters for best-fitted GMPEs

\begin{tabular}{|c|c|c|c|c|c|c|c|c|c|}
\hline \multirow{3}{*}{$\begin{array}{l}\text { Grading } \\
\text { parameter }\end{array}$} & \multicolumn{9}{|l|}{ GMPE } \\
\hline & \multicolumn{3}{|c|}{ Vrancea fore-arc } & \multicolumn{3}{|c|}{ Vrancea back-arc } & \multicolumn{3}{|c|}{ Crustal } \\
\hline & VEA15 & AEA15 & YEA97 & VEA15 & AEA15 & $\mathrm{AB} 03$ & CF08 & AEA05 & $\mathrm{AB} 10$ \\
\hline MEANNR & 0.317 & 0.286 & -0.075 & 0.265 & -0.251 & 0.005 & 0.378 & -0.626 & 1.172 \\
\hline$M E D N R$ & 0.316 & 0.323 & -0.028 & 0.284 & -0.271 & 0.094 & 0.488 & -0.527 & 1.253 \\
\hline$S T D N R$ & 0.995 & 1.106 & 0.919 & 1.216 & 1.323 & 2.010 & 1.399 & 1.418 & 2.268 \\
\hline$M E D L H$ & 0.508 & 0.432 & 0.559 & 0.437 & 0.384 & 0.152 & 0.359 & 0.444 & 0.068 \\
\hline$E D R$ & 1.01 & 1.10 & 1.27 & 1.13 & 1.22 & 1.55 & 1.42 & 1.63 & 2.03 \\
\hline
\end{tabular}


Pure and Applied Geophysics, 173, 2016, 1881-1905

Table 3. Weighing scheme employed in the PSHA for Romania

\begin{tabular}{llllll}
\hline Vrancea fore-arc & \multicolumn{2}{l}{ Vrancea back-arc } & Crustal & \\
\hline GMPE & $\begin{array}{l}\text { Weighting } \\
\text { factors }\end{array}$ & GMPE & $\begin{array}{l}\text { Weighting } \\
\text { factors }\end{array}$ & GMPE & $\begin{array}{l}\text { Weighting } \\
\text { factors }\end{array}$ \\
\hline VEA15 & 0.40 & VEA15 & 0.40 & CF08 & 0.40 \\
BCH15 & 0.30 & BCH15 & 0.40 & AEA05 & 0.40 \\
YEA97 & 0.30 & AB03 & 0.20 & AB10 & 0.20 \\
\hline
\end{tabular}




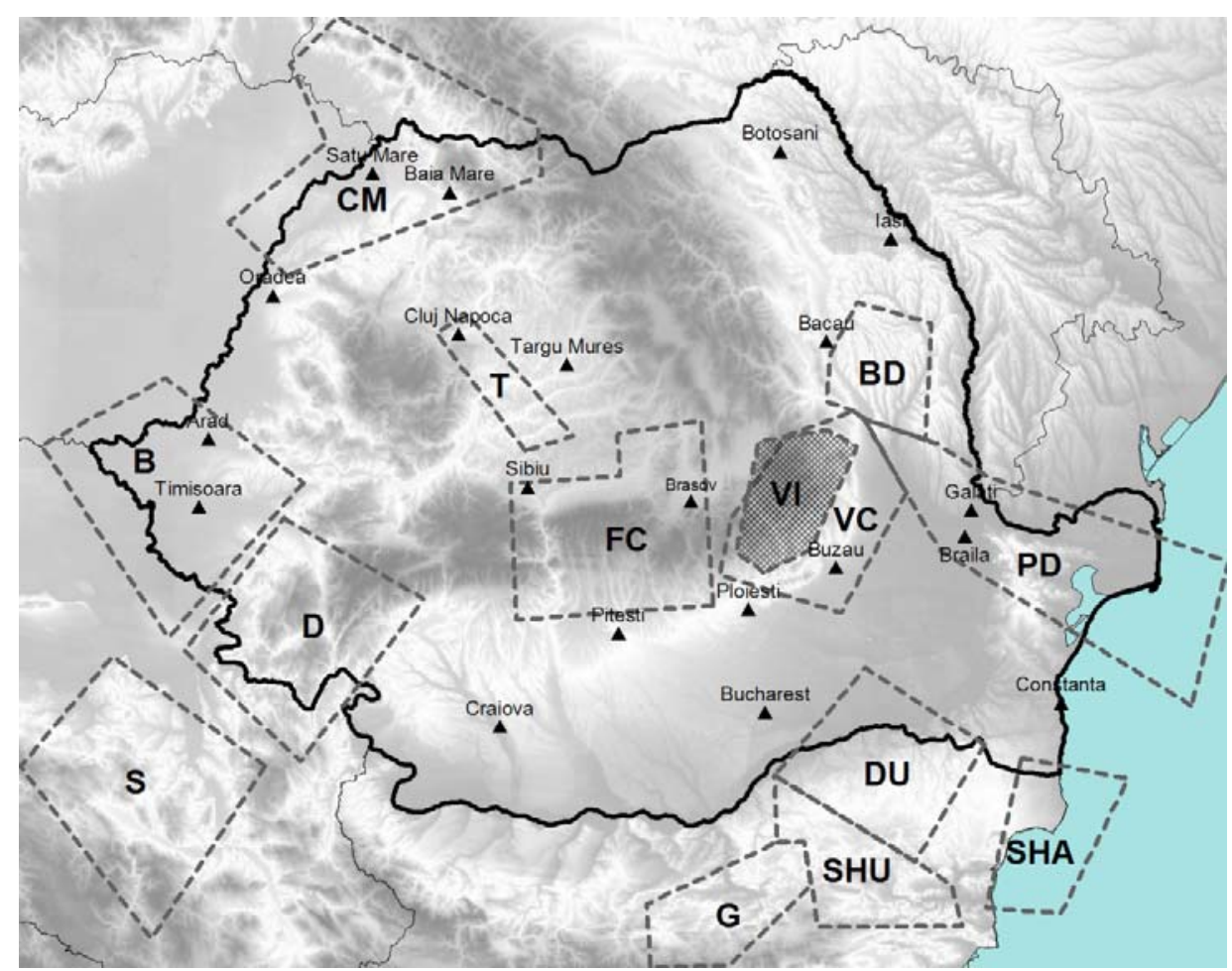

Figure 1. Sources contributing to the seismic hazard of Romania. The meanings of the acronyms on the map are: B- Banat, BD- Barlad Depression, CM - Crisana Maramures, D - Danubius, DU - Dulovo, FC - Fagaras Campulung, G - Gorna, PD - Pre-Dobrogea Depression, S - Serbia, SHA- Shabla, SHU Shumen, T - Transylvania, VC -Vrancea crustal and VI - Vrancea intermediate-depth. 


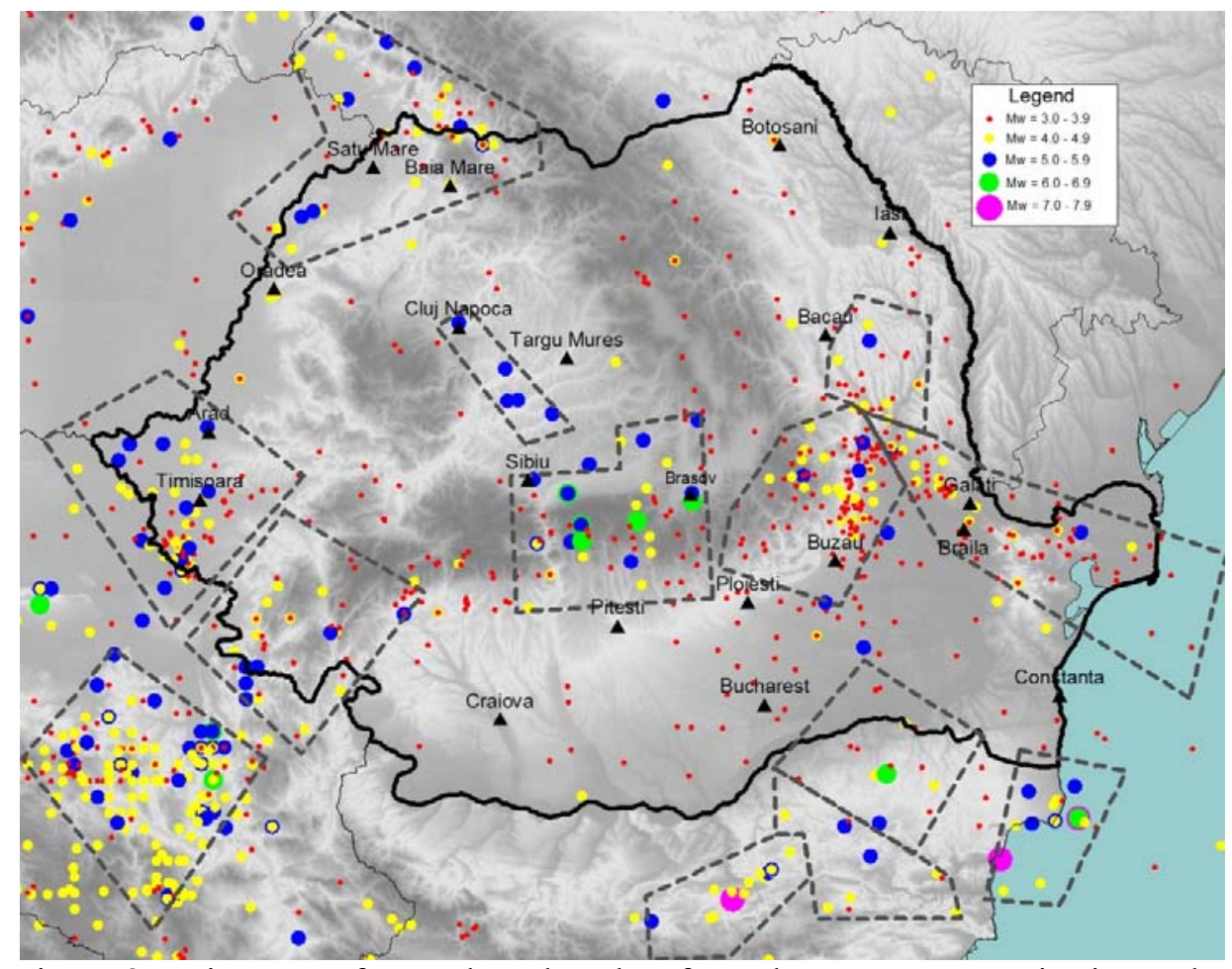

Figure 2. Epicentres of crustal earthquakes from the ROMPLUS seismic catalogue considered in the analysis

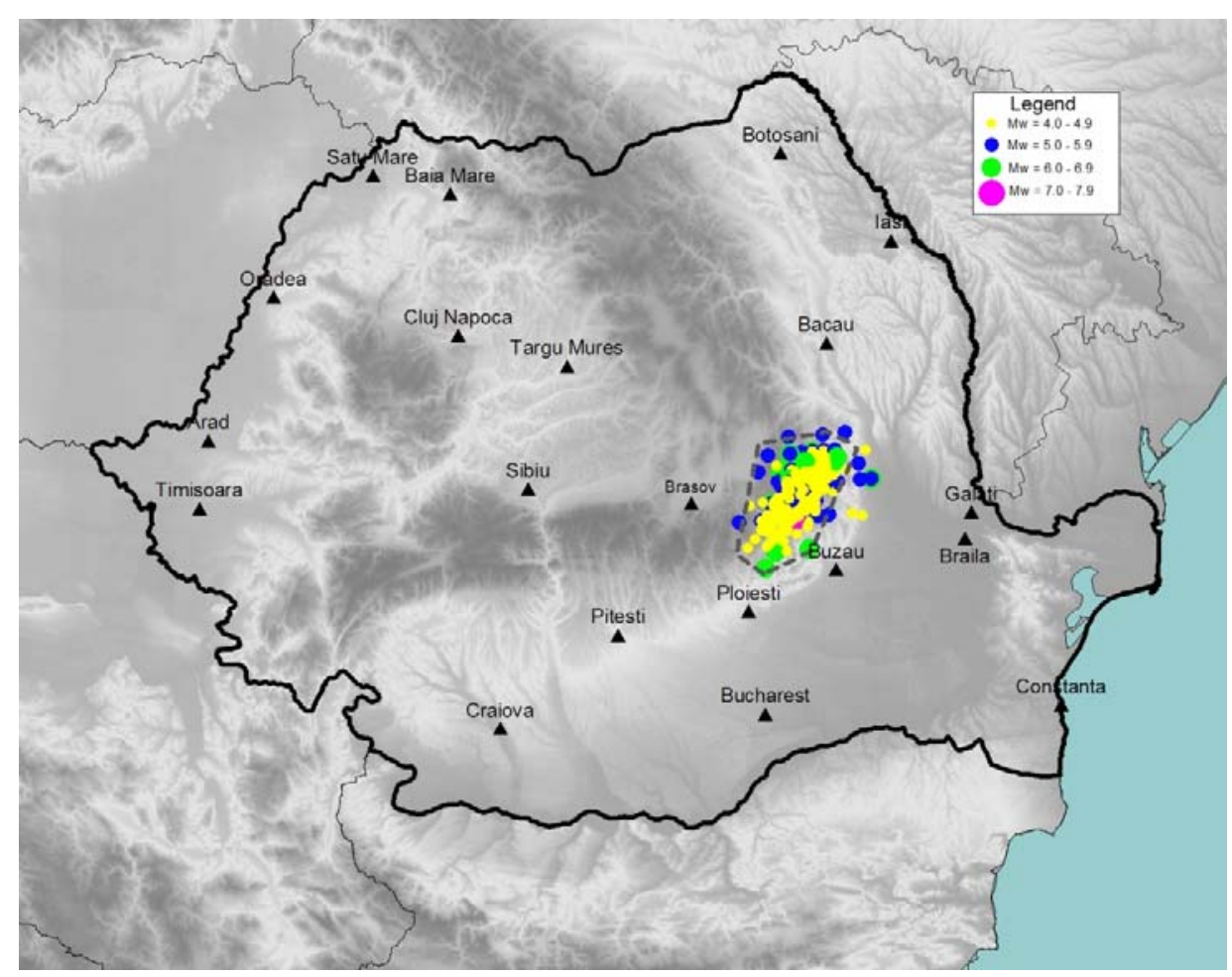


Pure and Applied Geophysics, 173, 2016, 1881-1905

Figure 3. Epicentres of intermediate-depth earthquakes considered in the analysis from the Vrancea subcrustal seismic source according to the ROMPLUS seismic catalogue 
Pure and Applied Geophysics, 173, 2016, 1881-1905
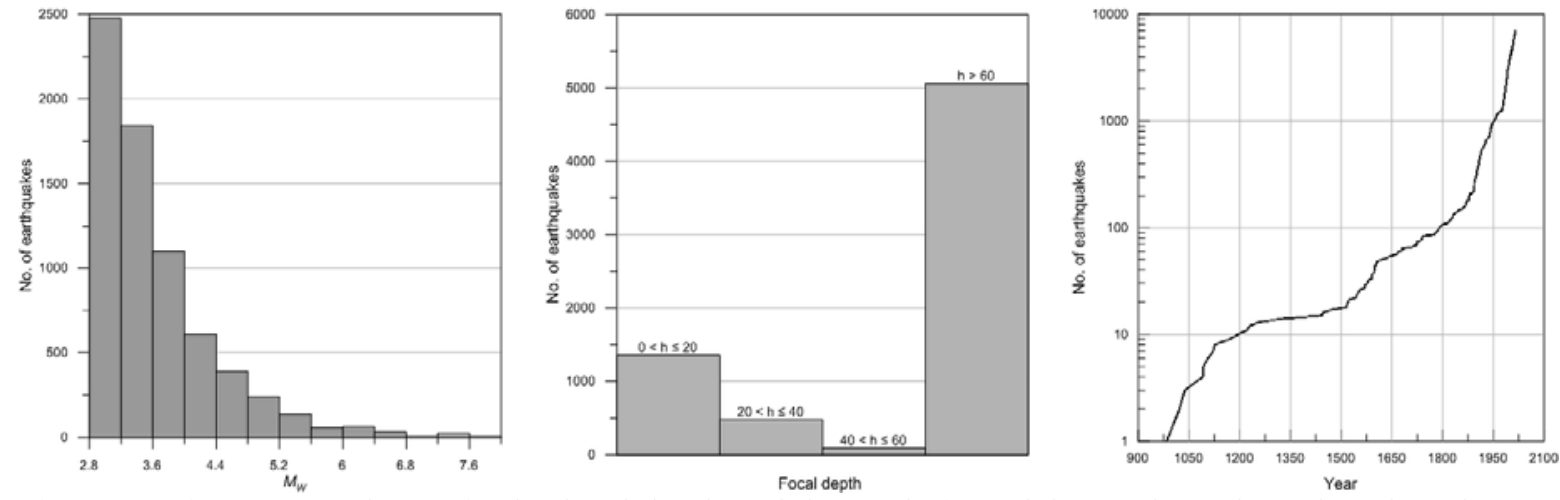

Figure 4. Histograms of magnitude, focal depth and the evolution of the total number of earthquakes with time in the ROMPLUS catalogue 

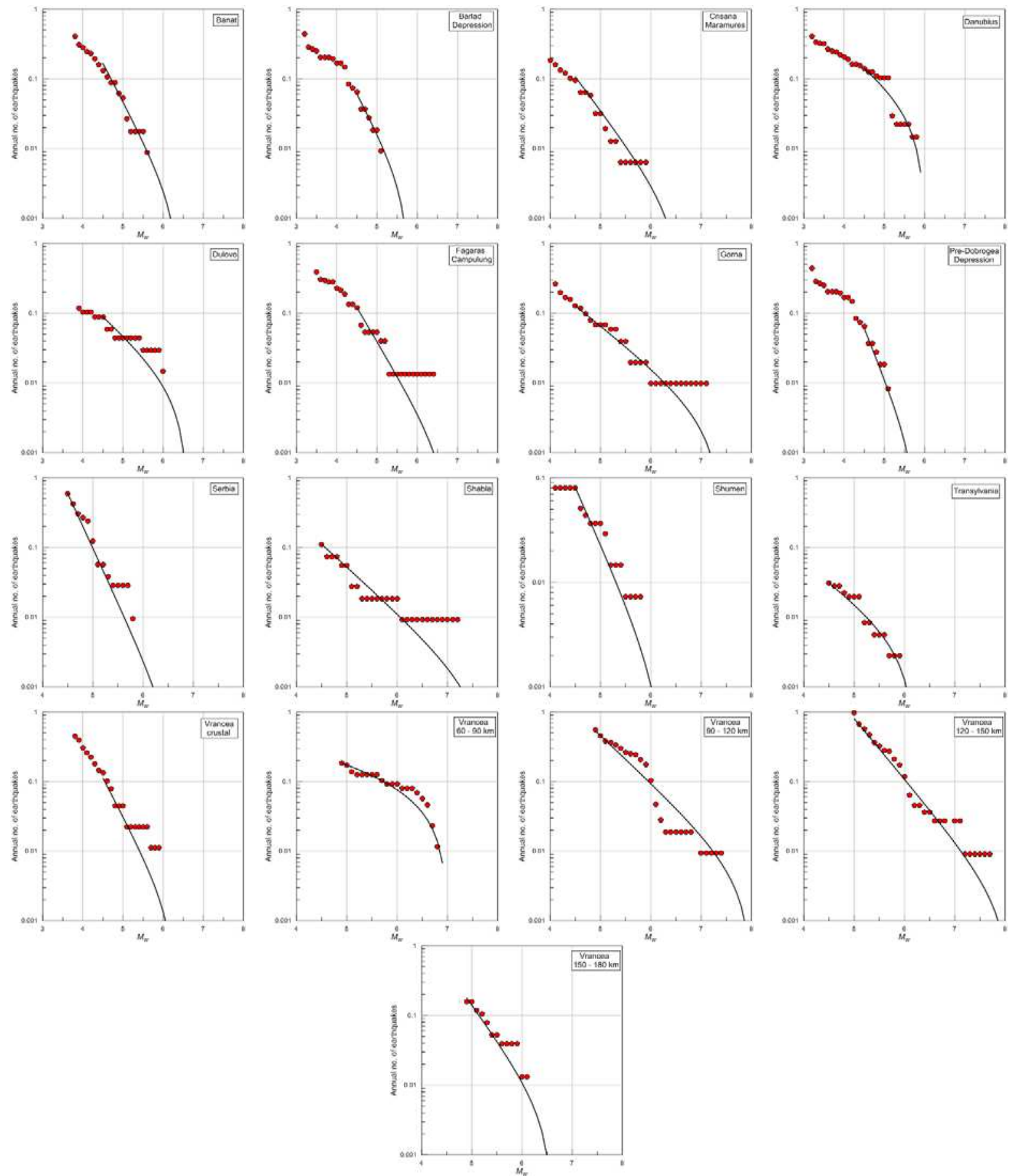

Figure 5. Comparison of observed seismicity with the fitted Gutenberg-Richter functions for all the seismic sources 


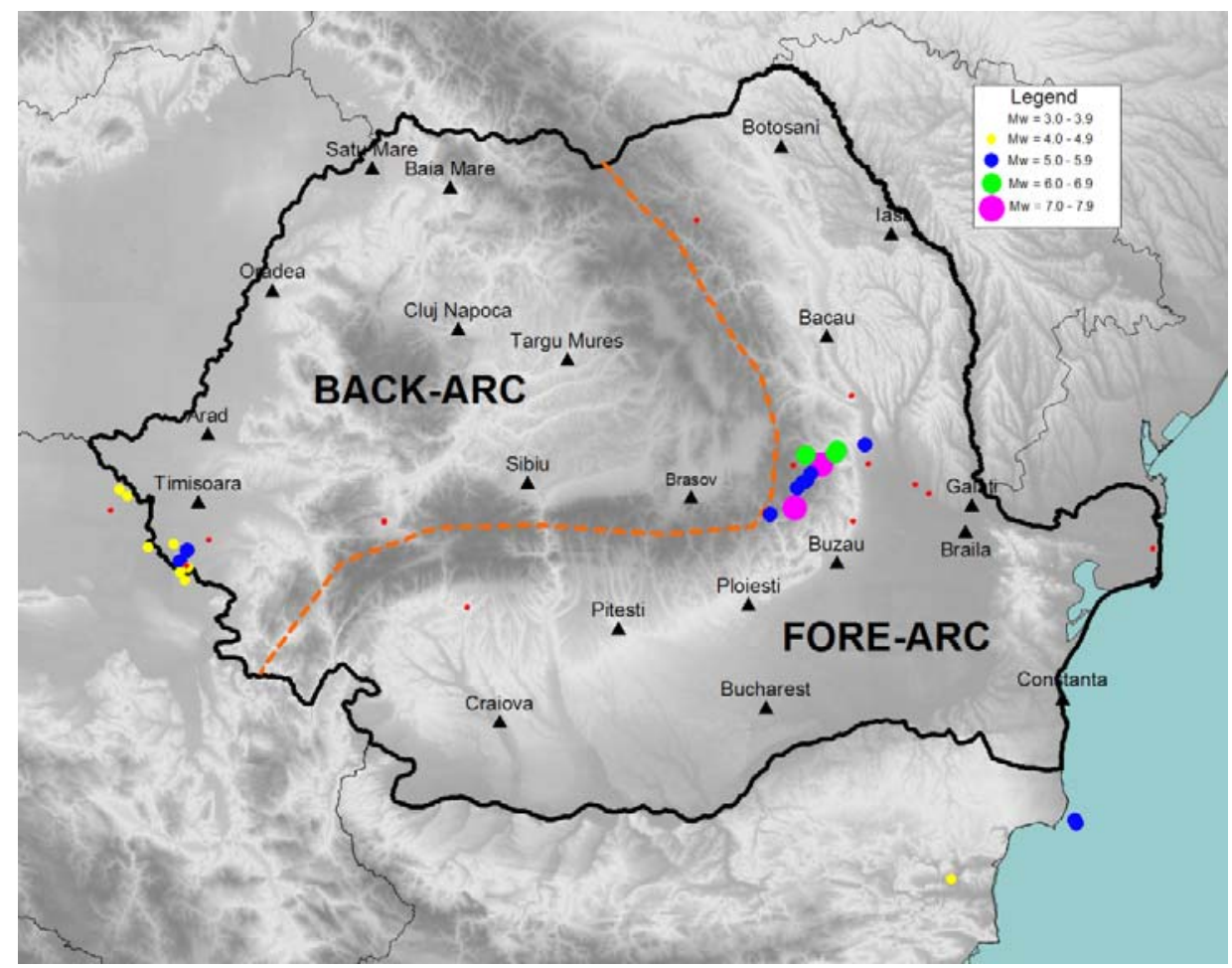

Figure 6. Epicentres of earthquakes with available ground-motion recordings 
Pure and Applied Geophysics, 173, 2016, 1881-1905
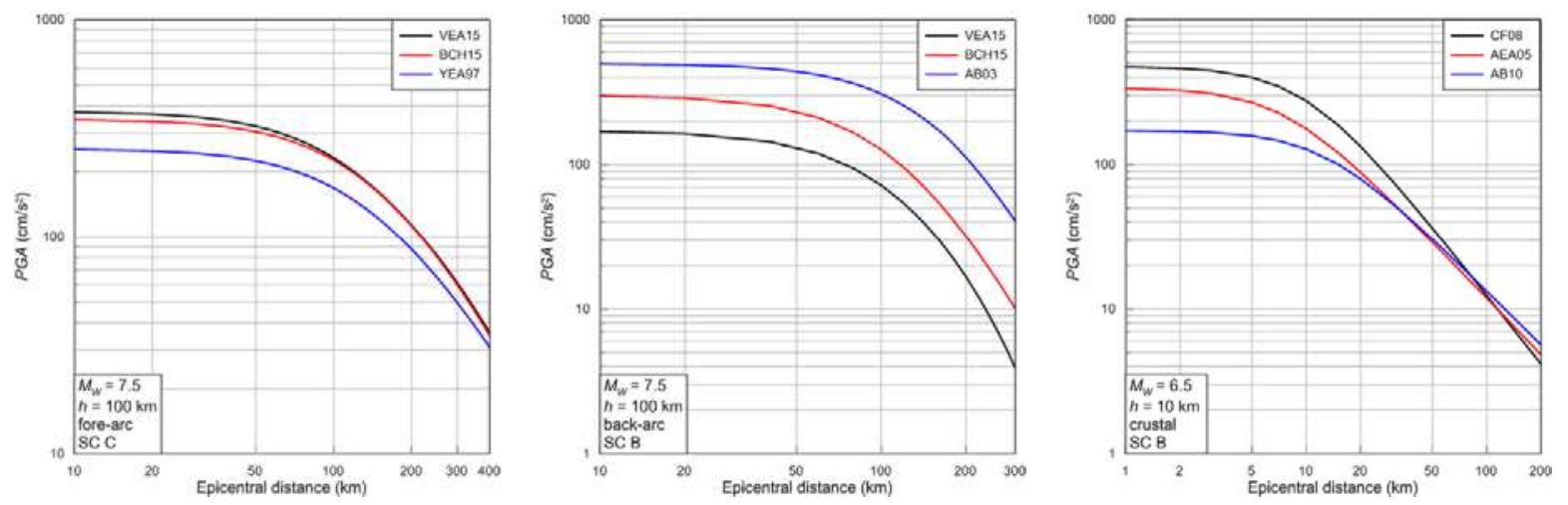

Figure 7. Comparison of median values of GMPEs used in PSHA for Romania 
Pure and Applied Geophysics, 173, 2016, 1881-1905

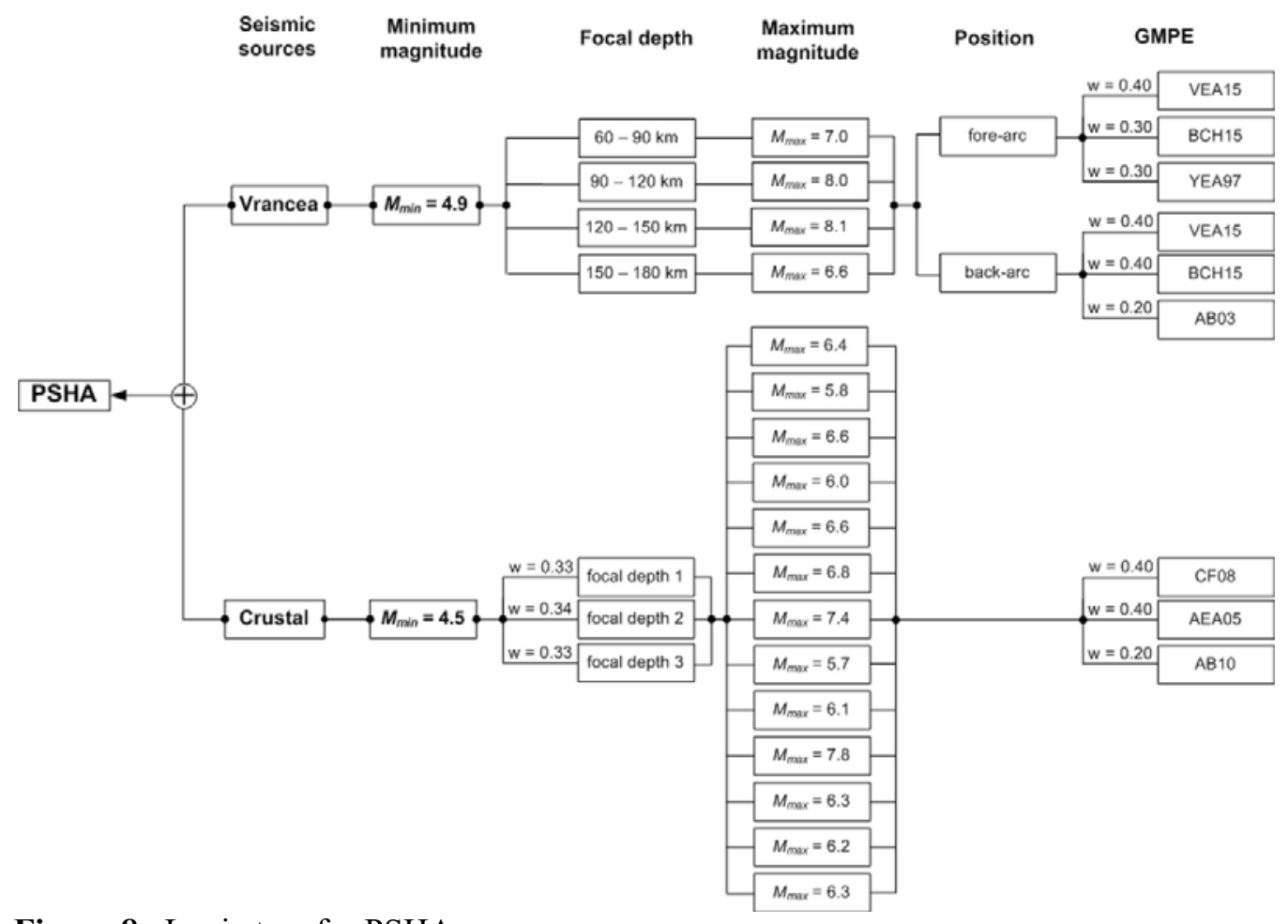

Figure 8. Logic tree for PSHA. 
Pure and Applied Geophysics, 173, 2016, 1881-1905

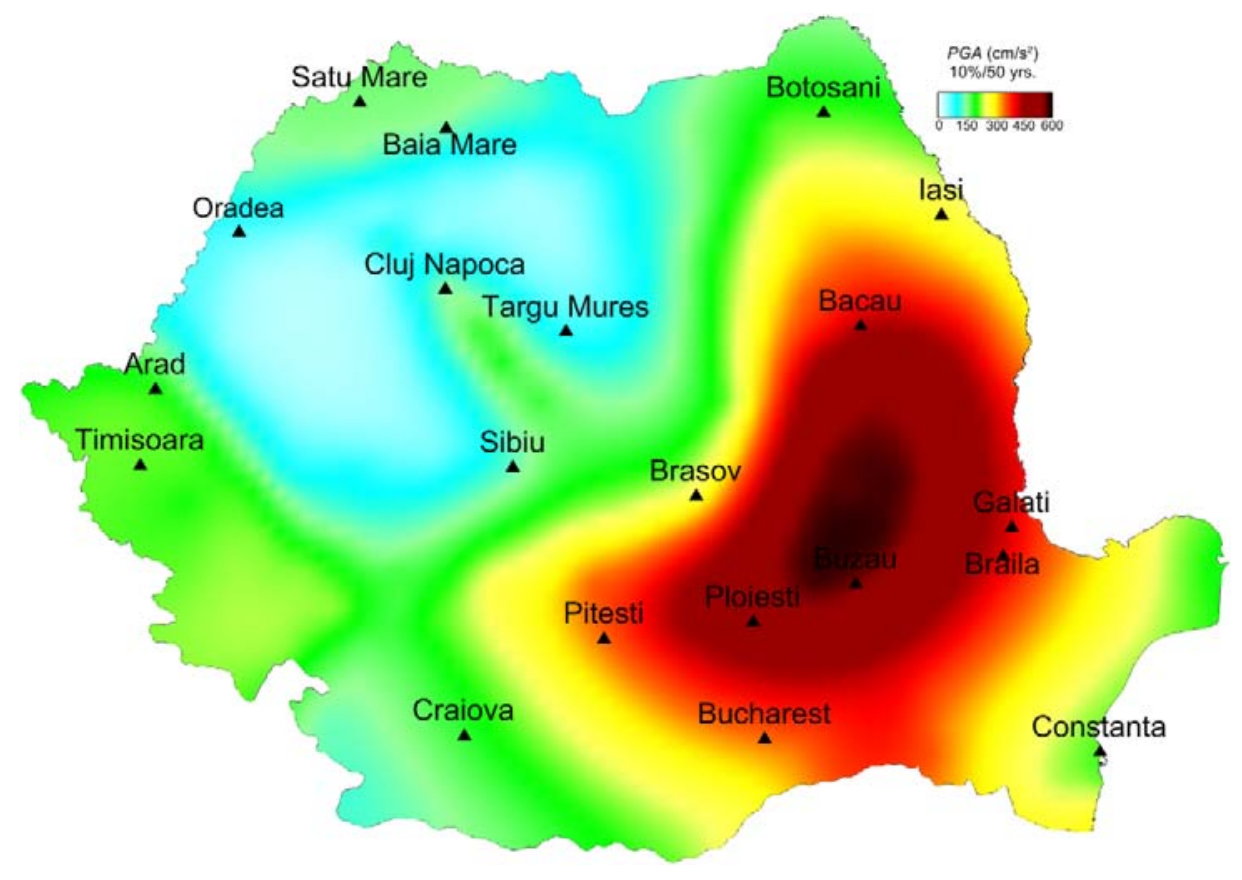

Figure 9. Seismic hazard map of Romania for the $P G A$ corresponding to an exceedance probability of $10 \%$ in 50 years (BIGSEES model) 
Pure and Applied Geophysics, 173, 2016, 1881-1905

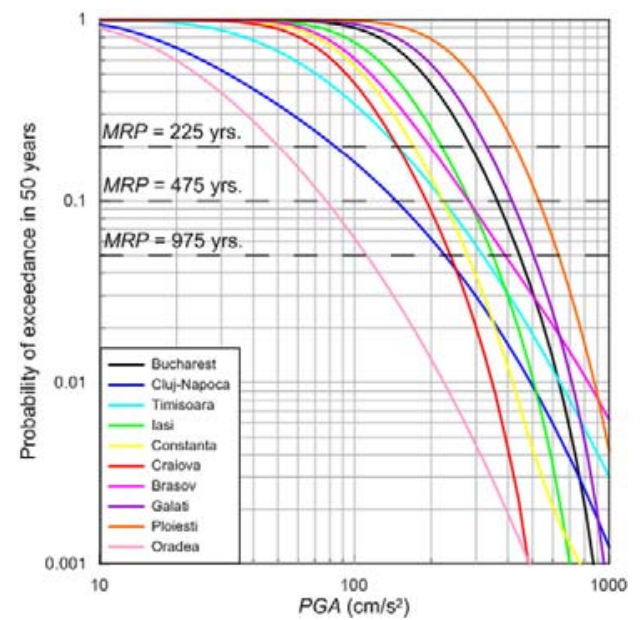

Figure 10. Mean hazard curves for $P G A$ for the ten most populous cities in Romania 
Pure and Applied Geophysics, 173, 2016, 1881-1905

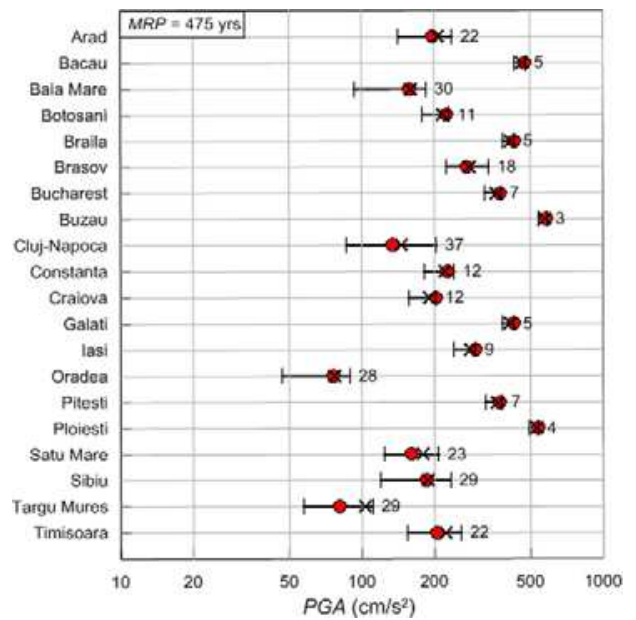

Figure 11. Comparison of peak ground acceleration values for a $M R I=475$ years (circles - means, crosses - medians; bars - 5th and 95th percentiles) and the corresponding uncertainty (label), as defined in the text 
Pure and Applied Geophysics, 173, 2016, 1881-1905

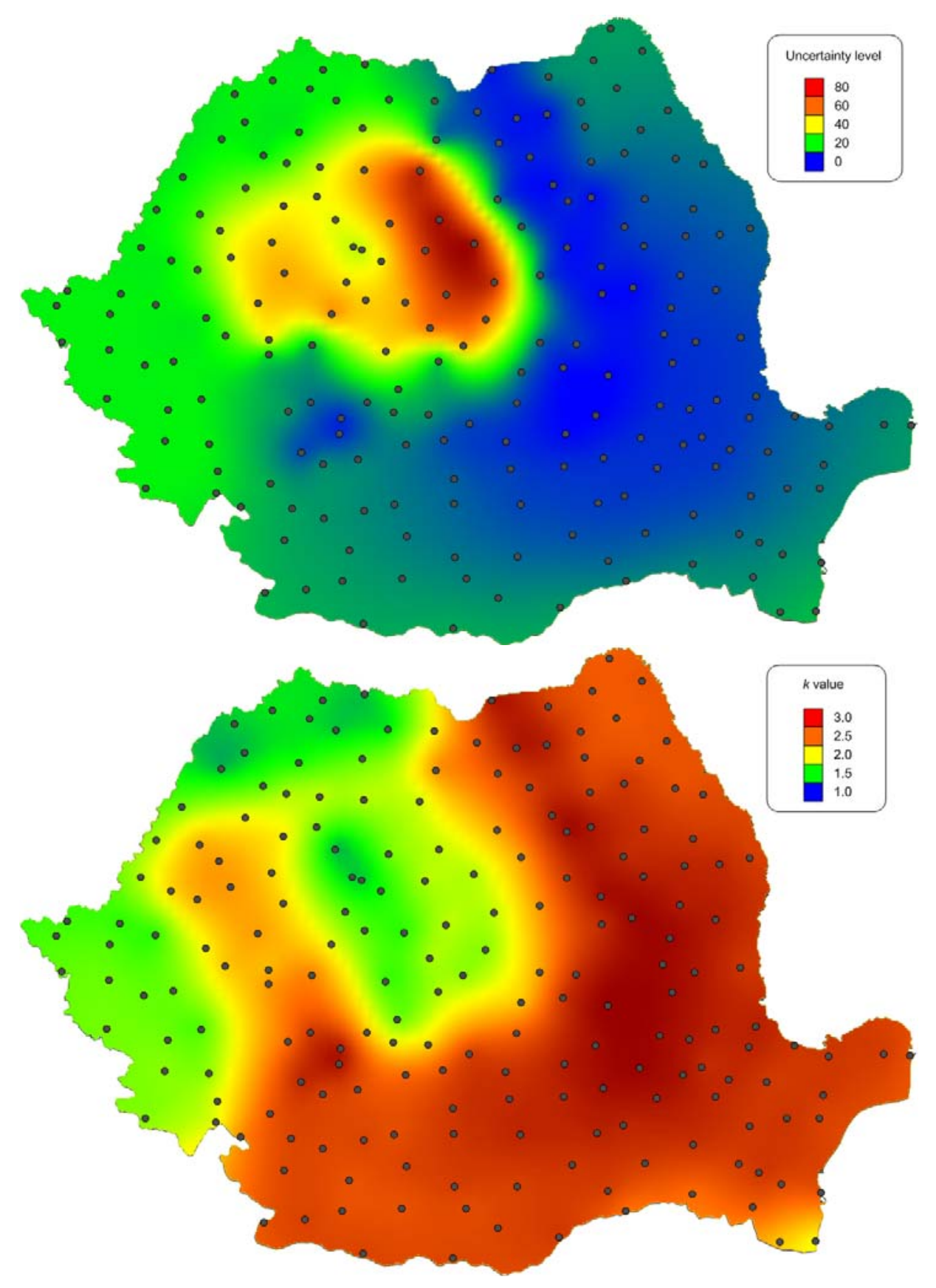




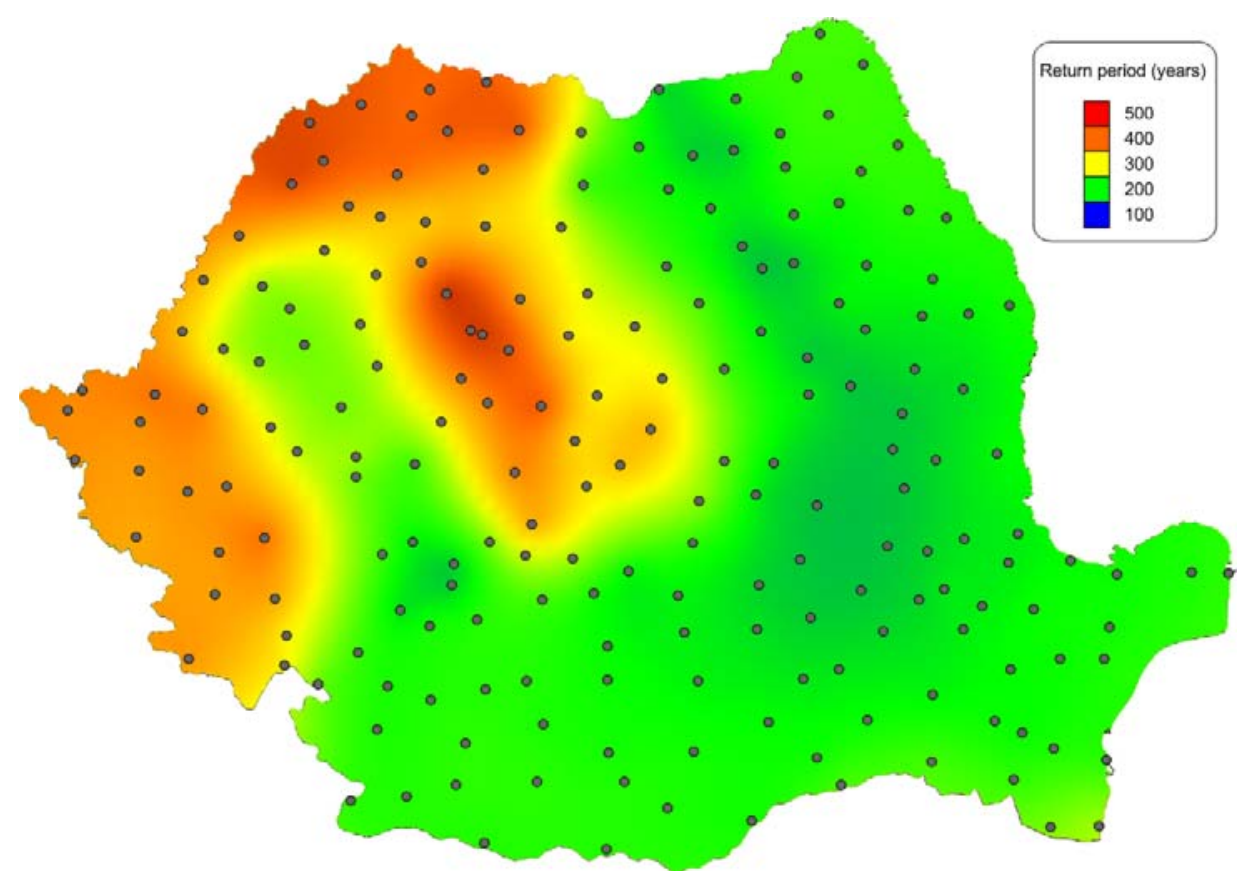

Figure 12. Maps of uncertainty, $k$ parameter and mean return period for structural failure (exceeding of ultimate limit state) for the BIGSEES model. 
Pure and Applied Geophysics, 173, 2016, 1881-1905

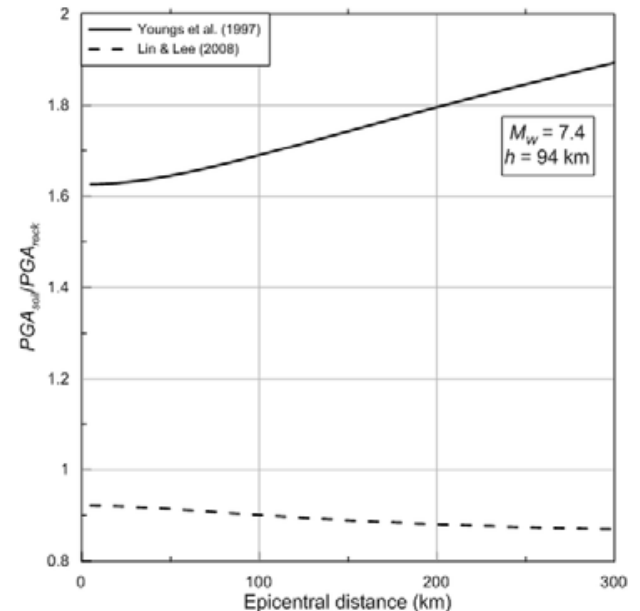

Figure 13. $P G A_{\text {soil }} / P G A_{\text {rock }}$ for the Youngs et al. (1997) and Lin and Lee (2008) ground-motion models 


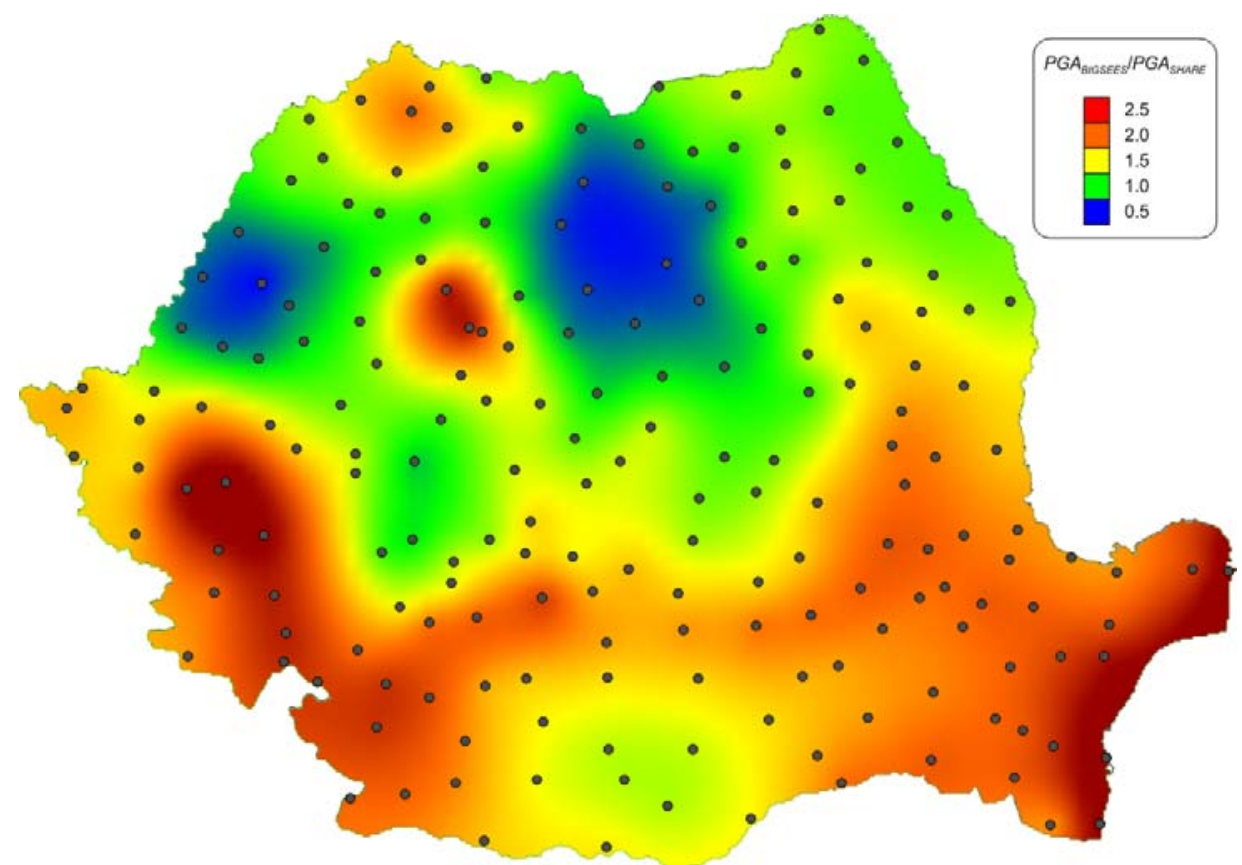

Figure 14. Ratio of $P G A$ s for an exceedance probability of $10 \%$ in 50 years obtained in this study (BIGSEES results on soil) and SHARE results (on rock) 
Pure and Applied Geophysics, 173, 2016, 1881-1905

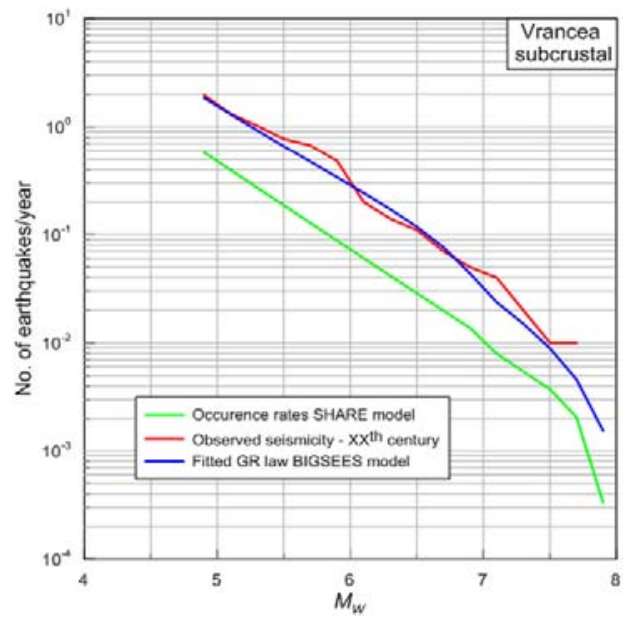

Figure 15. Comparison of the seismicity parameters adopted in the two seismic hazard models (BIGSSES and SHARE) and the observed seismicity of the $\mathrm{XX}^{\text {th }}$ century for the Vrancea subcrustal seismic source 
Pure and Applied Geophysics, 173, 2016, 1881-1905
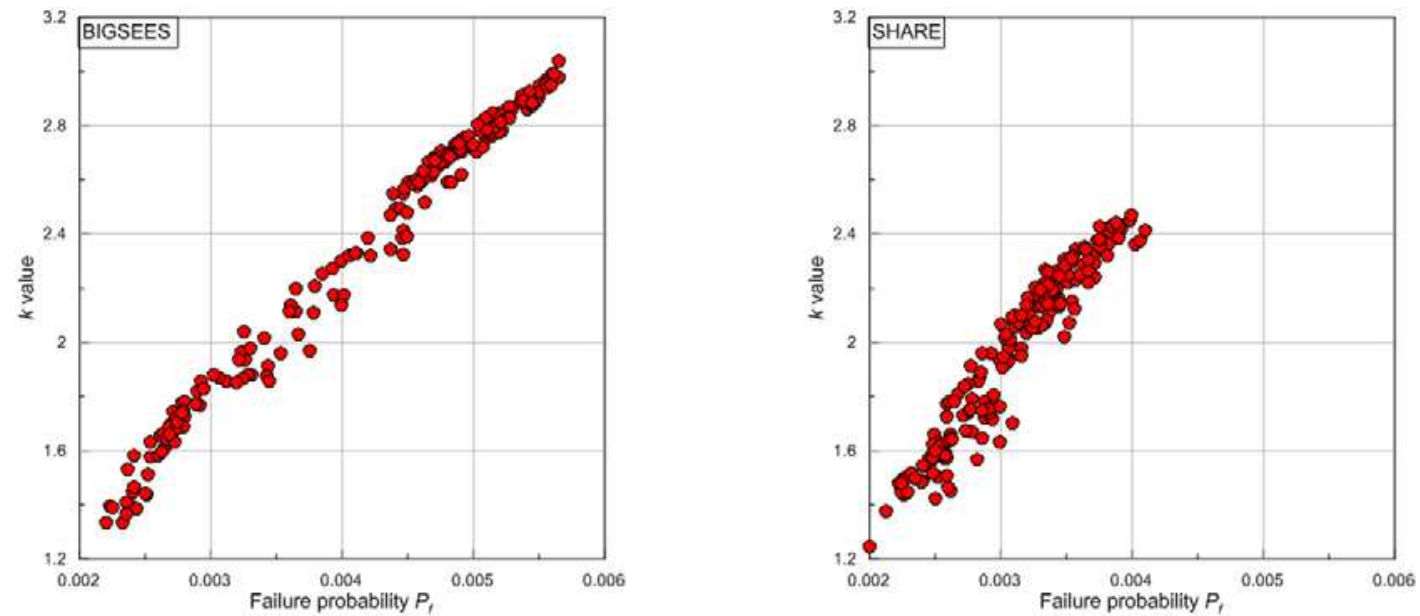

Figure 16. Slope of the seismic hazard curve ( $k$ value) against failure probability $P_{f}$ for 200 sites in Romania - BIGSEES model (left) and SHARE model (right) 
Pure and Applied Geophysics, 173, 2016, 1881-1905

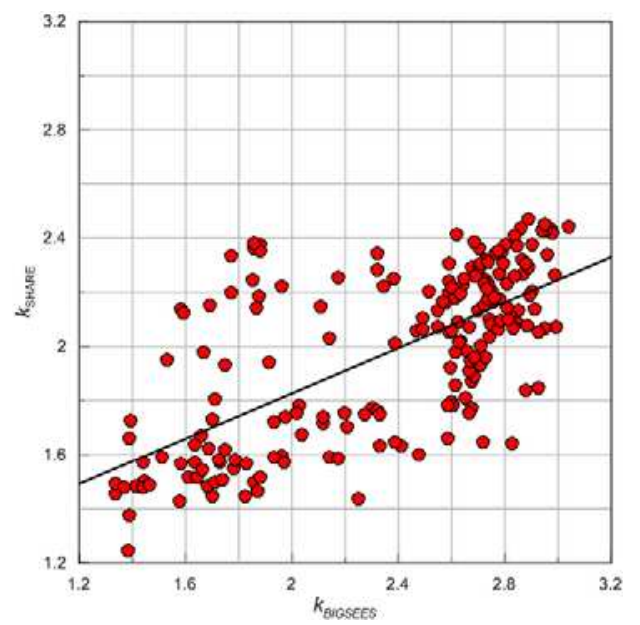

Figure 17. Relation between the $k$ values obtained in the two seismic hazard models (BIGSEES and SHARE). The black line shows the fitted trendline. 

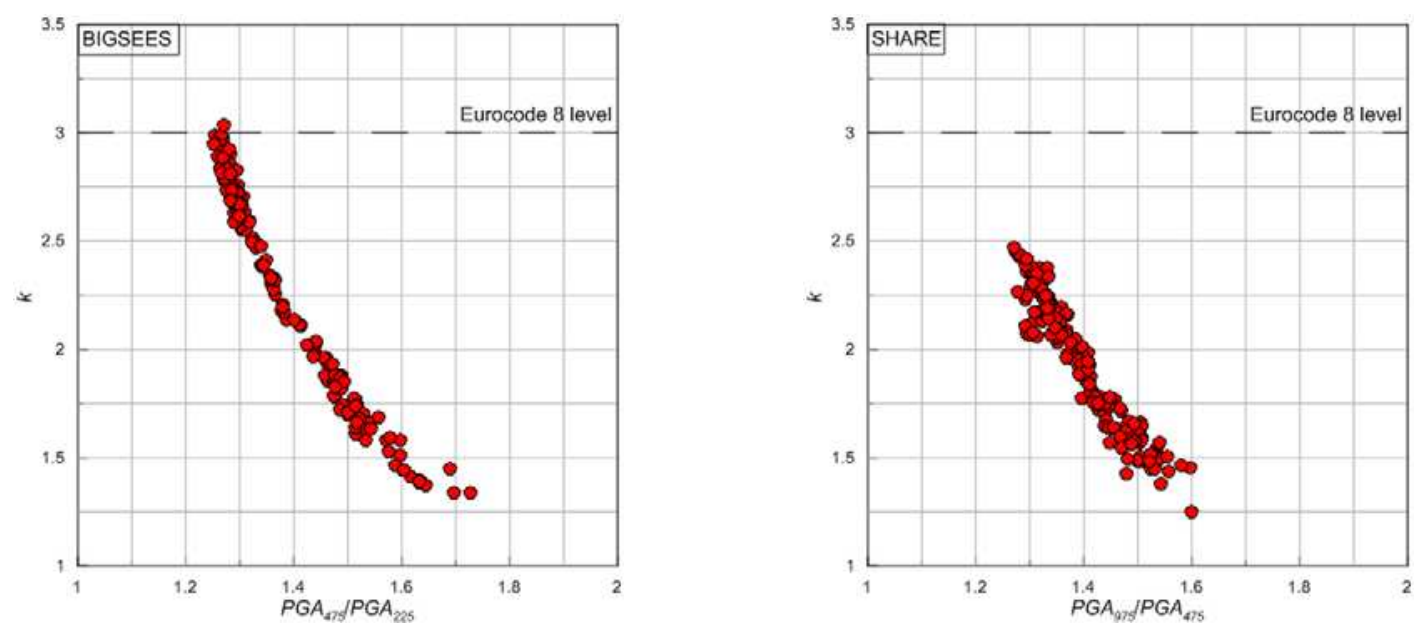

Figure 18. Relation between the $k$ value and the ratio of the $P G A$ with exceedance probability of $10 \%$ in 50 years to $20 \%$ in 50 years for the two seismic hazard models (BIGSEES and SHARE) 
Pure and Applied Geophysics, 173, 2016, 1881-1905

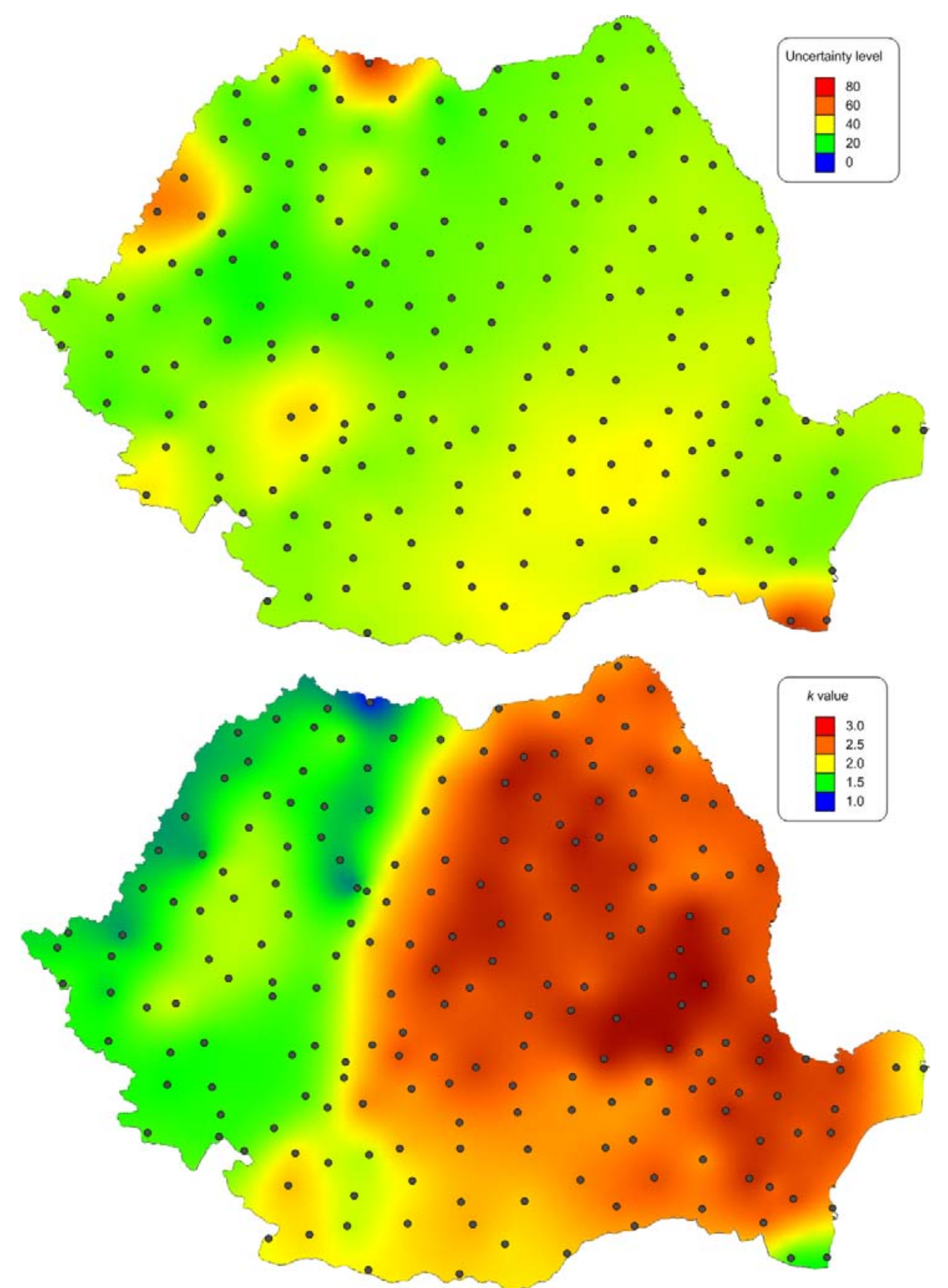

Figure 19. Maps of uncertainty level and $k$ parameter for the SHARE model 
Pure and Applied Geophysics, 173, 2016, 1881-1905

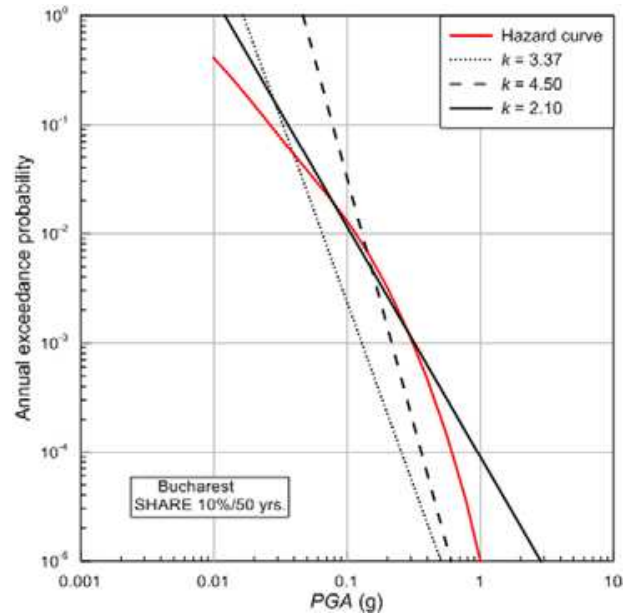

Figure 20. Comparison of seismic hazard curves for Bucharest for $P G A$ with different $k$ values 


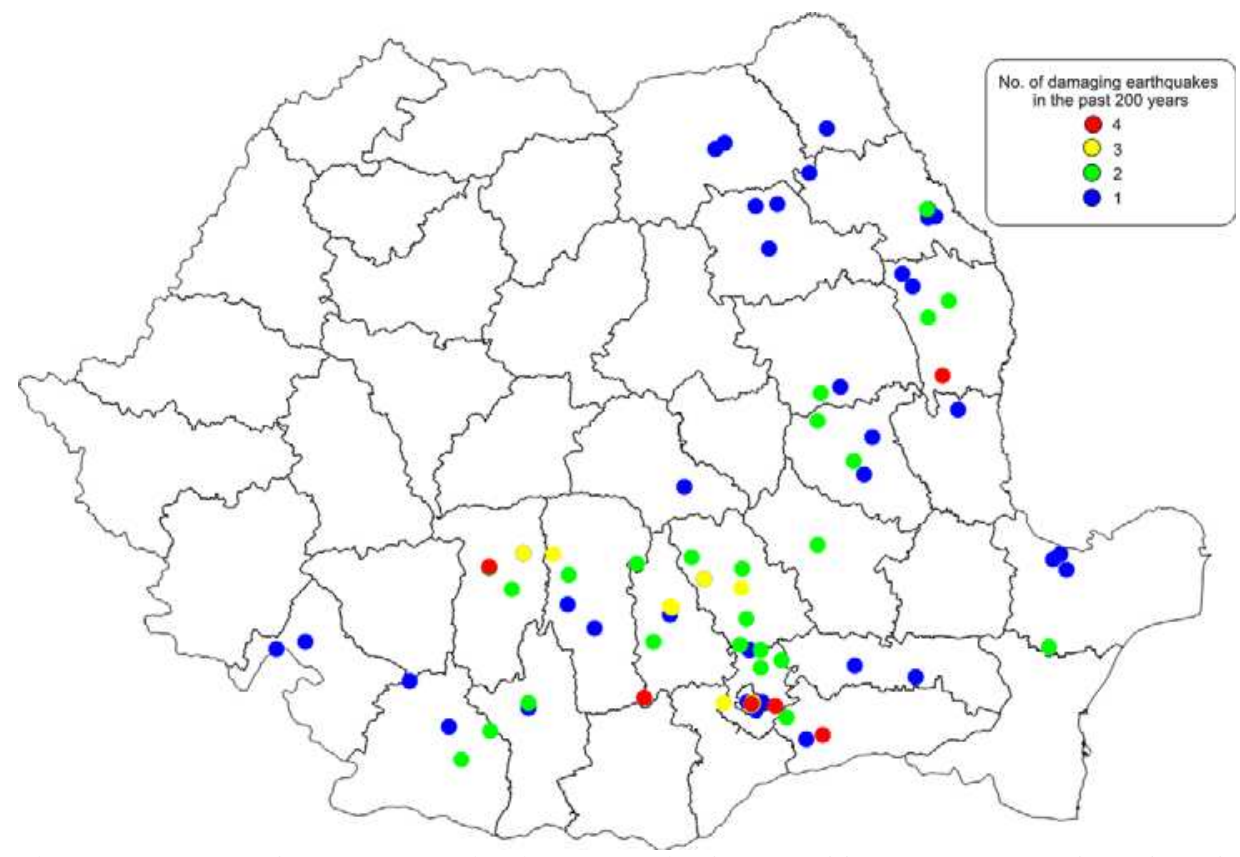

Figure 21. Map of 83 monasteries in Romania damaged by Vrancea earthquakes that occurred in the past 200 years with $M_{W} \geq 7.4$ (compiled after Mărmureanu, 2015) 